\title{
Capital Requirements in a Quantitative Model of Banking Industry Dynamics*
}

\author{
Dean Corbae \\ University of Wisconsin at Madison \\ Pablo D'Erasmo ${ }^{\dagger}$ \\ University of Maryland and Federal Reserve Bank of Philadelphia
}

September 18, 2013

\begin{abstract}
We develop a model of banking industry dynamics to study the quantitative impact of capital requirements on bank risk taking, commercial bank failure, and market structure. We propose a market structure where big, dominant banks interact with small, competitive fringe banks. The paper extends our previous work by letting banks accumulate securities like treasury bills and to undertake short-term borrowing when there are cash flow shortfalls. A nontrivial size distribution of banks arises out of endogenous entry and exit, as well as banks' buffer stocks of securities. We find that a $50 \%$ rise in capital requirements leads to a $45 \%$ reduction in exit rates of small banks and a more concentrated industry. Aggregate loan supply falls by $8.71 \%$ and interest rates rise by 50 basis points. The lower exit rate causes the tax/output rate necessary to fund deposit insurance to drop in half. Higher interest rates, on the other hand, result in a higher default frequency as well as a lower level of intermediated output. We also use the model to study the effect of lowering the rate different sized banks are charged when borrowing on their lending behavior studied by Kashyap and Stein [24].
\end{abstract}

*PRELIMINARY AND INCOMPLETE. The authors wish to thank Gianni DeNicolo, Matthias Kehrig, Skander Van Den Heuvel, as well as seminar participants at the Board of Governors, the Conference on Money and Markets at the University of Toronto, the Conference on Monetary Economics to honor the contributions of Warren Weber at the Atlanta Fed, the CIREQ Macroeconomics Conference, the BaumolTobin Anniversary Conference at NYU, the Econometric Society, Pittsburgh/Carnegie Mellon, Rochester, Rice, George Washington University, Maryland, McMaster, Ohio State, Queen's, the European University Institute and the Minneapolis Fed for helpful comments. The authors acknowledge the Texas Advanced Computing Center (TACC) at The University of Texas at Austin for providing HPC resources that have contributed to the research results reported within this paper. URL: http://www.tacc.utexas.edu.

${ }^{\dagger}$ The views expressed in this paper do not necessarily reflect those of the Federal Reserve Bank of Philadelphia or the Federal Reserve System. 


\section{Introduction}

The banking literature has focused on two main functions of bank capital. First, because of limited liability and deposit insurance banks have an incentive to engage in risk shifting. Requiring banks to hold a minimum ratio of capital to assets reduces the banks incentive to take risk. Second, bank capital acts like a buffer that may offset losses. In this paper we develop a structural model of banking industry dynamics to answer the following quantitative question: how much does an increase in capital requirements affect failure rates, interest rates, and market shares of large and small banks?

We endogenized market structure in an earlier paper (Corbae and D'Erasmo [12]), but limited the asset side of the bank balance sheet to loans and the liabilities side to deposits and equity. While loans and deposits are clearly the largest components of each side of the balance sheet of U.S. banks, this simplification does not admit ways for banks to insure themselves at a cost through holdings of securities like T-bills and borrowing in the interbank market to cover deposit shortfalls. In this paper, we extend the portfolio of bank assets in the above direction. Further we assume that banks are randomly matched with depositors and that these matches follow a markov process which is independently distributed across banks. Thus, we add fluctuations in deposits (which we term "liquidity shocks") to the model of the first paper.

We assume banks have limited liability. At the end of the period, banks may choose to exit in the event of cash shortfalls if their charter value is not sufficiently valuable. If a bank's charter value is sufficiently valuable, banks can use their stock of net securities as a buffer and borrow (whenever possible) to avoid being liquidated or issuing "expensive" equity. Thus, the extension allows us to consider banks undertaking precautionary savings in the face of idiosyncratic shocks as in a household income fluctuations problem but with a strategic twist since here, big banks have market power.

A benefit of our structural framework is that we can conduct policy counterfactuals. Our first set of policy experiments consider the effects of regulatory changes. In particular, in Subsection 7.1 we study a $50 \%$ rise in capital requirements (from $4 \%$ to $6 \%$ ) motivated by the changes recommended by Basel III. FDIC Rules and Regulations (Part 325) establishes the criteria and standards to calculate capital requirements and adequacy (see DSC Risk Management Manual of Examination Policies, FDIC, Capital (12-04)). Current capital requirements are based on the Basel II accord and define a bank as undercapitalized if the Tier 1 Risk-Based capital ratio is less than $4 \%$. We use the $4 \%$ risk-based capital ratio in our benchmark. Basel III establishes that banks will have to meet a minimum Tier 1 risk-based capital ratio of $6 \%$. The new rules regarding capital requirements will begin being implemented in different phases from 2013 to $2015 .{ }^{1}$ In our counterfactual we increase capital requirements to $6 \%$ to be consistent with the increase proposed in the Basel III guidelines.

We find that a $50 \%$ rise in capital requirements (from $4 \%$ to $6 \%$ ) leads to a $45 \%$ reduction in exit rates of small banks and a more concentrated industry. In order to meet the increased

\footnotetext{
${ }^{1}$ See a full description in BIS (2011) "Basel III: A global regulatory framework for more resilient banks and banking systems," pages 21-25.
} 
capital requirements, big banks lower their loan supply. The higher capital requirements results in a lower value for the bank and consequently the mass of fringe banks decreases by $14.64 \%$. These two effects account for the $8.71 \%$ reduction in loan supply and consequently a rise in loan interest rates by 50 basis points. The lower exit rate causes taxes/output used to pay for deposit insurance to drop in half. On the other hand, higher interest rates result in a $12 \%$ higher default frequency as well as an $8.78 \%$ lower aggregate level of intermediated output.

To understand the interaction between market structure and policy, we also conduct a counterfactual where we increase the entry cost for dominant banks to a level that prevents their entry. Since our benchmark model nests a dominant bank model with a perfectly competitive sector, this counterfactual implies that we move endogenously to an environment with only perfectly competitive banks. In Subsection 7.2 we find that capital ratios are much larger in the benchmark economy than in the one with only competitive banks. The reason is that the environment with dominant banks is riskier (a higher default frequency and volatility of all aggregates). We document that strategic loan supply by dominant banks results in an important source of amplification of shocks. We also find, as one would expect, that in a perfectly competitive industry the loan interest rate is lower than in the benchmark, resulting in lower default frequencies and higher intermediated output. Finally, we find that certain cyclical properties are quite different between an imperfectly competitive model and one with perfect competition. For instance, markups are countercyclical in the imperfectly competitive model (as they are in the data), while they are procyclical in the model with perfect competition.

In order to determine the case for any capital requirement at all, in Subsection 7.3 we assess the implications of removing capital requirements entirely. As expected, both big and small banks hold less securities. However, the big bank also strategically lowers loan supply in order to raise interest rates and profitability. Higher profitability raises entry rates by fringe banks.

Basel III also calls for banks to maintain a "countercyclical" capital buffer of up to $2.5 \%$ of risk-based Tier 1 capital. As explained in BIS (2011) the aim of the "countercyclical" buffer is to use a buffer of capital to protect the banking sector from periods of excess aggregate credit growth and potential future losses. According to Basel III, a buffer of $2.5 \%$ will be in place only during periods of credit expansion. ${ }^{2}$ In Subsection 7.4 we plan to run a counterfactual where the capital requirement increases by $1 \%$ during periods of economic expansion, so the capital requirement fluctuates between $6 \%$ and $7 \%$.

Our second set of policy experiments in Subsection 7.5 consider the effects of "monetary" policy changes on the bank balance sheet and lending decisions. In an important paper, Kashyap and Stein [24] studied whether the impact of Fed policy on lending behavior is stronger for banks with less liquid balance sheets (where balance sheet strength is measured as the ratio of securities plus federal funds sold to total assets). The mechanism they test

\footnotetext{
${ }^{2}$ BIS (2010) "Guidance for national authorities operating the countercyclical capital buffer" establishes that credit/GDP is a reference point in taking buffer decisions but suggests examples of other variables that may be useful indicators such as asset prices, spreads, real GDP growth.
} 
relies on the idea that (p.410) "banks with large values of this ratio should be better able to buffer their lending activity against shocks in the availability of external finance, by drawing on their stock of liquid assets." One of their measures of monetary policy is the federal funds rate. They find strong evidence of an effect for small banks (those in the bottom 95\% of the distribution). In this section, we conduct a similar exercise by running a set of two stage regressions on a pseudo panel of banks from our model and find that the results are largely consistent with the empirical evidence presented in Kashyap and Stein [24]. ${ }^{3}$

The computation of this model is a nontrivial task. In an environment with aggregate shocks, all equilibrium objects, such as value functions and prices, are a function of the distribution of banks. The distribution of banks is an infinite dimensional object and it is computationally infeasible to include it as a state variable. Thus, we solve the model using an extension of the algorithm proposed by Krusell and Smith [25] or Farias et. al. [19] adapted to this environment. This entails approximating the distribution of banks by a finite number of moments. We use mean asset and deposit levels of fringe banks joint with the asset level of the big bank since the dominant bank is an important player in the loan market. Furthermore, when making loan decisions, the big bank needs to take into account how changes in its behavior affects the total loan supply of fringe banks. This reaction function also depends on the industry distribution. For the same reasons as stated above, in the reaction function we approximate the behavior of the fringe segment of the market with the dynamic decision rules (including entry and exit) of the "average" fringe bank, i.e. a fringe bank that holds the mean asset and deposit levels. ${ }^{4}$

Our paper is related to the following literature. Van Den Heuvel [30] was one of the first quantitative general equilibrium models to study the welfare impact of capital requirements with perfect competition. In a similar environment, Aliaga-Diaz and Olivero [1] analyze whether capital requirements can amplify business cycles. Also in a competitive environment, Repullo and Suarez [28] compare the relative performance of several capital regulation regimes and study their cyclical implications. In these papers, constant returns and perfect competition implies that there is an indeterminate distribution of bank sizes, so they do not examine the differential effect on big and small banks and how the strategic interaction affects outcomes when implementing a tighter capital requirement. ${ }^{5}$

In a closely related paper, De Nicolo et. al. [13] study the bank decision problem in a more general model than ours. ${ }^{6}$ On the other hand, since they study only a decision problem,

\footnotetext{
${ }^{3}$ Our data, the same as Kashyap and Stein, is not rich enough to study heterogeneity at the matched lender/borrower lending level. In an important new empirical paper, Jimenez, et. al. [23] use an exhaustive Spanish dataset to study bank risk taking with heterogeneous borrowers. In section 8 on Directions for Future Research we discuss how our framework can be applied to study such datasets.

${ }^{4} \mathrm{An}$ appendix to this paper states the algorithm we use to compute an approximate Markov perfect industry equilibrium.

${ }^{5}$ Other recent quantitative general equilibrium papers by Gertler and Kiyotaki [21] and Cociuba et. al. [11] consider the effects of credit policies and macro prudential policies on financial intermediation and risk taking incentives also with an indeterminate size distribution.

${ }^{6}$ Other papers that analyze the individual bank decision problem and capital requirements are Zhu [31] and Estrella [17]
} 
they do not consider the impact of such policies on interest rates on loans, the equilibrium bank size distribution, etc. Another related paper is that of Allen et.al. [2]. In their static framework, banks may hold levels of capital above the levels required by regulation due to incentives to monitor. They analyze how exogenous changes in market structure (i.e. the level of competition) affects the predictions of the model. Our paper is the first one with an endogenous bank size distribution. This allows us to to quantify how capital requirements affect failure rates and endogenous market shares of large and small banks.

The paper is organized as follows. While we have documented a large number of banking facts that are relevant to the current paper in our previous work [12], Section 2 documents a new set of banking data facts relevant to this paper. Section 3 lays out a simple model environment to study bank risk taking and loan market competition. Section 4 describes a markov perfect equilibrium of that environment. Section 5 discusses how the preference and technology parameters are chosen and Section 6 provides results for the simple model. Section 7 conducts our counterfactuals, first for regulatory changes and second for monetary policy changes: (i) the effects of an increase in bank capital requirements on business failures and banking stability in our benchmark economy with imperfect competition (Subsection 7.1); (ii) how competition interacts with capital requirement policy changes (Subsection 7.2); (iii) risk taking in the absence of capital requirements (Subsection 7.3); (iv) the impact of "countercyclical capital requirements" (Subsection 7.4); and (v) the impact of easier "monetary policy" (lower borrowing terms) on bank lending behavior (Subsection 7.5).

\section{Banking Data Facts}

In our previous paper [12], we documented the following facts for the U.S. using data from the Consolidated Report of Condition and Income (known as Call Reports) that insured banks submit to the Federal Reserve each quarter. ${ }^{7}$ Entry is procyclical and exit by failure is countercyclical (correlation with detrended GDP equal to 0.62 and -0.25 , respectively). Almost all entry and exit is by small banks. Loans and deposits are procyclical (correlation with detrended GDP equal to 0.58 and 0.10, respectively). Bank concentration has been rising; the top 4 banks have $35 \%$ of the loan market share. There is evidence of imperfect competition: the net interest margin is 4.6\%; markups exceed $70 \%$; the Lerner Index exceeds $35 \%$; the Rosse-Panzar $H$ statistic (a measure of the sensitivity of interest rates to changes in costs) is significantly lower than the perfect competition number of $100 \%$ (specifically, $H=$ 52). Loan Returns, margins, markups, delinquency rates and charge-offs are countercyclical. ${ }^{8}$

\footnotetext{
${ }^{7}$ The number of institutions and its evolution over time can be found at http://www2.fdic.gov/hsob/SelectRpt.asp?EntryTyp=10

. Balance Sheet and Income Statements items can be found at https://cdr.ffiec.gov/public/.

${ }^{8}$ The countercyclicality of margins and markups is important. Building a model consistent with this is a novel part of our previous paper [12]. The endogenous mechanism in our papers works as follows. During a downturn, there is exit by smaller banks. This generates less competition among existing banks which raises the interest rate on loans. But since loan demand is inversely related to the interest rate, the ensuing increase in interest rates (barring government intervention) lowers loan demand even more thereby amplifying the
} 
Before turning to a set of new facts that this paper is intended to study, we first present some of the main balance sheet items of commercial banks (as a fraction of total assets) by bank size in years 1990 and 2010.

Table 1: Bank's Balance Sheet

\begin{tabular}{l|cc|cc}
\hline \hline Fraction Total Assets (\%) & \multicolumn{2}{|c}{1990} & \multicolumn{2}{c}{2010} \\
\hline & Bottom 99\% & Top 1\% & Bottom 99\% & Top 1\% \\
\hline Cash & 7.25 & 10.98 & 7.95 & 7.66 \\
Securities & 18.84 & 13.30 & 18.37 & 15.79 \\
Loans & 49.28 & 53.20 & 55.08 & 41.06 \\
\hline & & & & \\
\hline Deposits & 69.70 & 62.75 & 64.37 & 56.02 \\
Fed Funds and Repos & 4.17 & 7.54 & 1.30 & 1.20 \\
Equity Capital & 6.20 & 4.66 & 9.94 & 10.66 \\
\hline \hline
\end{tabular}

Note: Data corresponds to commercial banks in the US. Source: Consolidated Report of Condition and Income.

We note that loans (which we will denote $\ell_{t}^{\theta}$ for a bank of size $\theta$ in period $t$ ) and deposits (denoted $d_{t}^{\theta}$ ) represent the largest asset and liability category for both bank sizes. Securities are the second largest asset component and it is larger for small banks than for big banks. For the model which follows, one can think of lumping cash and securities together (denoted $a_{t}^{\theta}$ ), fed funds borrowed and repos (denoted $B_{t}^{\theta}$ ) and equity capital (denoted $e_{t}^{\theta}$ ).

Since we are interested in the effects of capital and liquidity requirements on bank behavior and loan rates, we organize the data to understand differences in capital holdings across banks of different sizes. Prior to 1980, no formal uniform capital requirements were in place. In 1981, the Federal Reserve Board and the Office of the Comptroller of the Currency announced a minimum total capital ratio (equity plus loan-loss reserves to total assets) of 6 percent for community banks and 5 percent for larger regional institutions. In 1985, a unified minimum capital requirement was set at 5.5\% for all banks (see International Lending Supervision Act of 1983).

As we discussed in the Introduction, current regulation in the U.S. (based on Basel II guidelines) establishes that each individual bank, each Bank Holding Company (BHC), and each bank within a BHC is subject to three basic capital requirements: (i) Tier 1 Capital to Total Assets must be above 4\% (if greater than 5\% banks are considered well capitalized); (ii) Tier 1 Capital to Risk-Weighted Assets must exceed 4\% (if greater than 6\% banks are considered well capitalized); and (iii) Total Capital to Risk-Weighted Assets must be larger than $8 \%$ (if greater than $10 \%$ banks are considered well capitalized). ${ }^{9}$

downturn. In this way our model is the first to use imperfect competition to produce endogenous loan amplification in the banking sector.

${ }^{9}$ Tier 1 capital is composed of common and preferred equity shares (a subset of total bank equity). Tier 
Given the timing in our model, we can express the risk-weighted capital ratio as $e_{t}^{\theta} / \ell_{t}^{\theta}$ and the capital to asset ratio as $e_{t}^{\theta} /\left(\ell_{t}^{\theta}+a_{t+1}^{\theta}\right)$. Table 1 documents that equity to asset ratios are larger for small banks in the early sample and the relation changes for the latest year in our sample. Further, since we are interested in bank capital ratios by bank size, Figure 1 presents the evolution of Tier 1 Capital to Asset Ratio and Tier 1 Capital to risk-weighted Asset Ratio for Top 1\% and Bottom 99\% banks when sorted by assets.

Figure 1: Bank Capital by Size

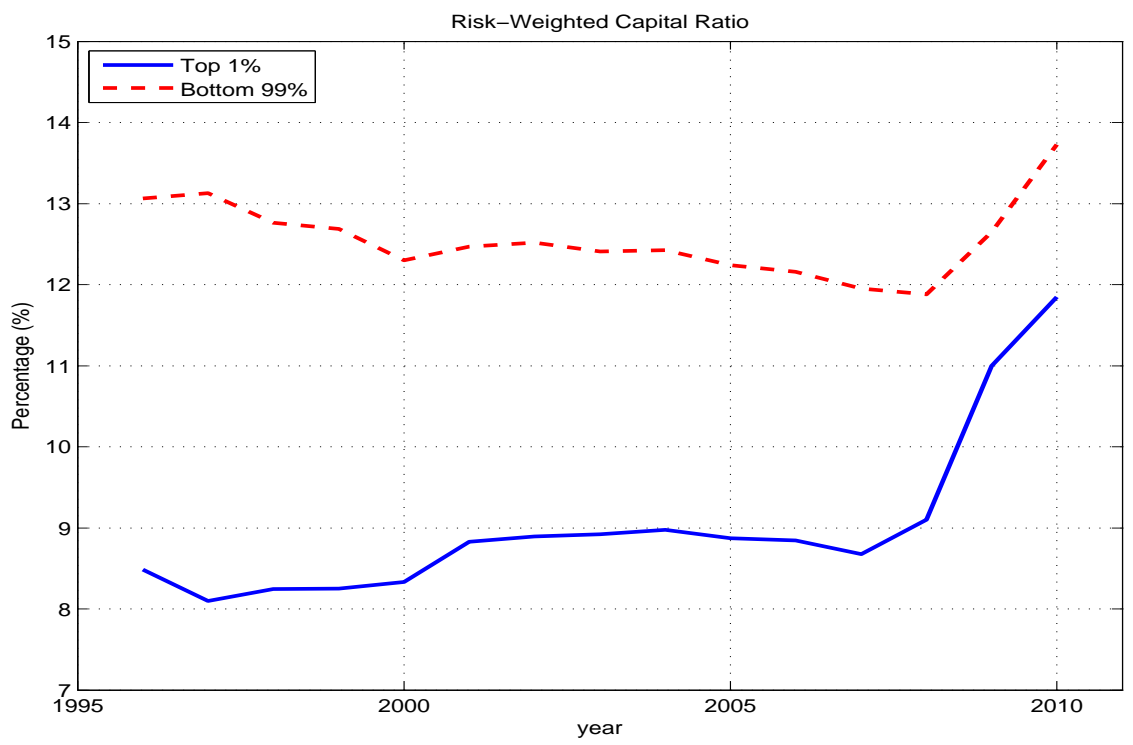

Note: Data corresponds to commercial banks in the US. Source: Consolidated Report of Condition and Income. GDP (det) refers to detrended real log-GDP. The trend is extracted using the H-P filter with parameter 6.25 .

In all periods, risk-weighted capital ratios are lower for large banking institutions than those for small banks. ${ }^{10}$ The fact that capital ratios are above what regulation defines as well capitalized is suggestive of a precautionary motive.

Figure 2 presents the evolution of detrended risk-weighted Tier 1 Capital Ratio over time against detrended GDP.

2 capital includes subordinated debt and hybrid capital instruments such as mandatory convertible debt. Total capital is calculated by summing Tier 1 capital and Tier 2 capital.

${ }^{10}$ Capital Ratios based on total assets (as opposed to risk-weighted) present a similar pattern. 
Figure 2: Bank Capital and Business Cycles

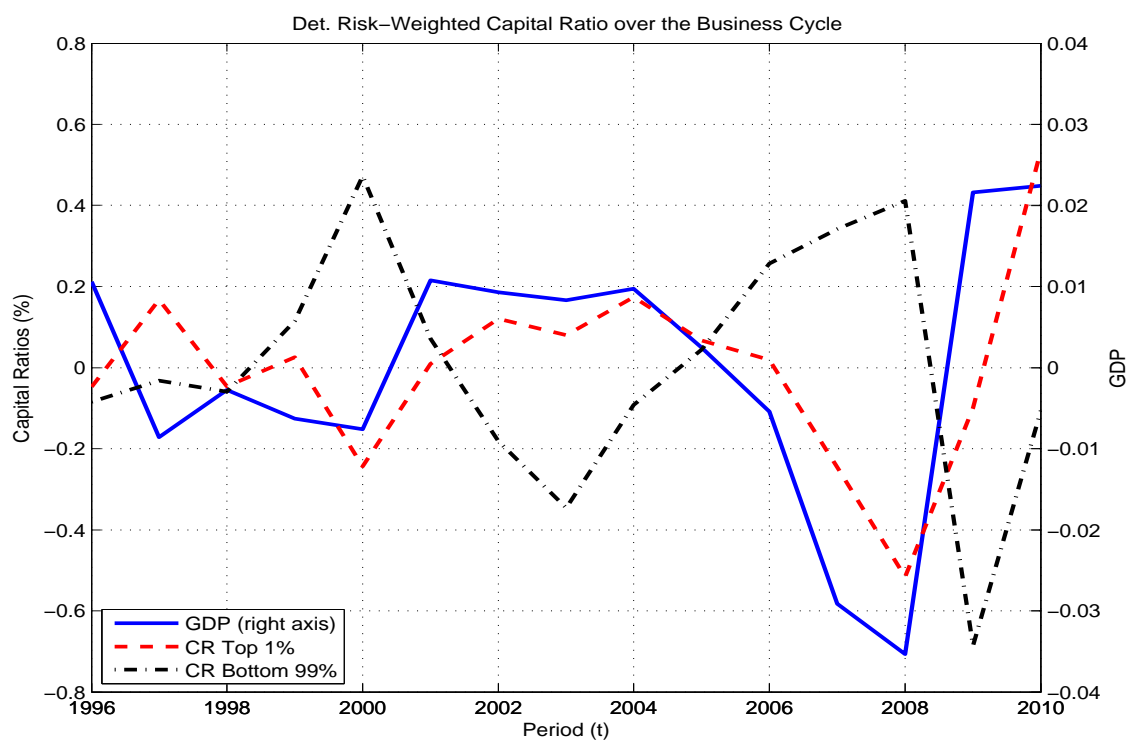

Note: Data corresponds to commercial banks in the US. Source: Consolidated Report of Condition and Income. GDP (det) refers to detrended real log-GDP. The trend is extracted using the H-P filter with parameter 6.25 .

The correlation of the Tier 1 capital ratio and GDP is -0.76 and -0.36 for top $1 \%$ and bottom $99 \%$ banks respectively. The fact that the correlation for small banks is less countercyclical than for large banks is suggestive that small banks try to accumulate capital during good times to build a buffer against bank failure in bad times. In fact, the correlation between Tier 1 Capital to total Assets and GDP is -0.45 for the top $1 \%$ banks and 0.48 for the bottom $99 \%$ banks.

\section{Environment}

Our dynamic banking industry model is based upon the static framework of Allen and Gale [3] and Boyd and DeNicolo [9]. In those models, there is an exogenous number of banks that are Cournot competitors either in the loan and/or deposit market. ${ }^{11}$ We endogenize the number of banks by considering dynamic entry and exit decisions and apply a version of the Markov Perfect equilibrium concept in Ericson and Pakes [18] augmented with a competitive fringe as in Gowrishankaran and Holmes [22].

Specifically, time is infinite. Each period, a mass $N$ of one period lived ex-ante identical borrowers and a mass $\Xi$ of one period lived ex-ante identical households (who are potential

\footnotetext{
${ }^{11}$ Martinez-Miera and Repullo [26] also consider a dynamic model, but do not endogenize the number of banks.
} 
depositors) are born.

\subsection{Borrowers}

Borrowers demand bank loans in order to fund a project. The project requires one unit of investment at the beginning of period $t$ and returns at the end of the period:

$$
\begin{cases}1+z_{t+1} R_{t} & \text { with prob } p\left(R_{t}, z_{t+1}\right) \\ 1-\lambda & \text { with prob }\left[1-p\left(R_{t}, z_{t+1}\right)\right]\end{cases}
$$

in the successful and unsuccessful states respectively. Borrower gross returns are given by $1+z_{t+1} R_{t}$ in the successful state and by $1-\lambda$ in the unsuccessful state. The success of a borrower's project, which occurs with probability $p\left(R_{t}, z_{t+1}\right)$, is independent across borrowers but depends on the borrower's choice of technology $R_{t} \geq 0$ and an aggregate technology shock at the end of the period denoted $z_{t+1}$ (the dating convention we use is that a variable which is chosen/realized at the end of the period is dated $t+1)$. The aggregate technology shock $z_{t} \in\left\{z_{b}, z_{g}\right\}$ with $z_{b}<z_{g}$ (i.e. good and bad shocks) evolves as a Markov process $F\left(z^{\prime}, z\right)=\operatorname{prob}\left(z_{t+1}=z^{\prime} \mid z_{t}=z\right)$.

At the beginning of the period when the borrower makes his choice of $R_{t}, z_{t+1}$ has not been realized. As for the likelihood of success or failure, a borrower who chooses to run a project with higher returns has more risk of failure and there is less failure in good times. Specifically, $p\left(R_{t}, z_{t+1}\right)$ is assumed to be decreasing in $R_{t}$ and $p\left(R_{t}, z_{g}\right)>p\left(R_{t}, z_{b}\right)$. While borrowers are ex-ante identical, they are ex-post heterogeneous owing to the realizations of the shocks to the return on their project. We envision borrowers either as firms choosing a technology which might not succeed or households choosing a house that might appreciate or depreciate.

There is limited liability on the part of the borrower. If $r_{t}^{L}$ is the interest rate on bank loans that borrowers face, the borrower receives $\max \left\{z_{t+1} R_{t}-r_{t}^{L}, 0\right\}$ in the successful state and 0 in the failure state. Specifically, in the unsuccessful state he receives $1-\lambda$ which must be relinquished to the lender. Table 2 summarizes the risk-return tradeoff that the borrower faces if the industry state is $\zeta$.

Table 2: Borrower's Problem

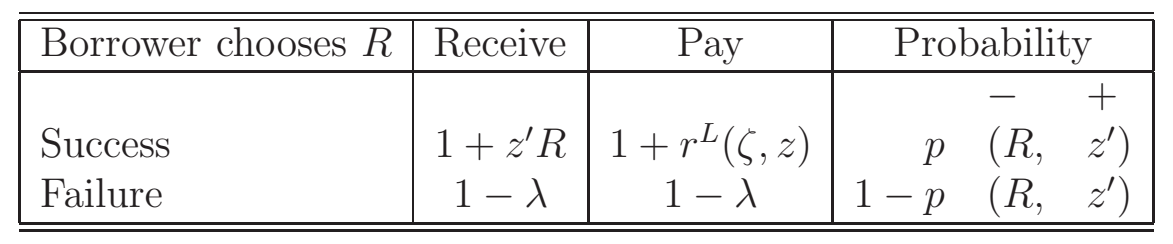

Borrowers have an outside option (reservation utility) $\omega_{t} \in[\underline{\omega}, \bar{\omega}]$ drawn at the beginning of the period from distribution function $\Omega\left(\omega_{t}\right)$. 


\subsection{Depositors}

Households are endowed with 1 unit of the good and have strictly concave preferences denoted $u\left(C_{t}\right)$. Households have access to a risk free storage technology yielding $1+\bar{r}$ with $\bar{r} \geq 0$ at the end of the period. They can also choose to supply their endowment to a bank or to an individual borrower. If the household deposits its endowment with a bank, they receive $r_{t}^{D}$ whether the bank succeeds or fails since we assume deposit insurance. If they match with a borrower, they are subject to the random process in (1). At the end of the period they pay lump sum taxes $\tau_{t+1}$ which are used to cover deposit insurance for failing banks.

\subsection{Banks}

We assume there are two types of banks $\theta \in\{b, f\}$ for "big" and small "fringe" respectively. We assume that there is a representative big bank. ${ }^{12}$ If active, the big bank is a Stackelberg leader each period choosing a level of loans before fringe banks make their choice of loan supply. Consistent with the assumption of Cournot competition, the dominant bank understands that its choice of loan supply will influence interest rates. Fringe banks take the interest rate as given when choosing loan supply.

At the beginning of each period banks are matched with a random number of depositors. Specifically, in period $t$, bank $i$ of type $\theta$ chooses how many deposits $d_{i, t}^{\theta}$ to accept up to a capacity constraint $\delta_{t}$, i.e. $d_{i, t}^{\theta} \leq \delta_{t}$ where $\delta_{t} \in\left\{\delta^{1}, \ldots, \delta^{n}\right\} \subseteq \mathbb{R}_{+}$. The capacity constraint evolves according to a Markov process given by $G^{\theta}\left(\delta_{t+1}, \delta_{t}\right)$. The value of $\delta$ for a new entrant is drawn from the probability distribution $G^{\theta, e}(\delta)$.

We denote loans made by bank $i$ of type $\theta$ to borrowers at the beginning of period $t$ by $\ell_{i, t}^{\theta}$. Bank $i$ can also choose to hold securities $a_{i, t+1}^{\theta} \in \mathbb{R}_{+}$. We think of securities as associated with T-bills plus loans to other banks. We assume net securities have return equal to $r_{t}^{a}$. If the bank begins with $\tilde{a}_{i, t}^{\theta}$ net securities, the bank's feasibility constraint at the beginning of the period is given by:

$$
\tilde{a}_{i, t}^{\theta}+d_{i, t}^{\theta} \geq \ell_{i, t}^{\theta}+a_{i, t+1}^{\theta} .
$$

In Corbae and D'Erasmo [12] we document differences in bank cost structure across size. We assume that banks pay proportional non-interest expenses (net non-interest income) that differ across banks of different sizes, which we denote $c_{i}^{\theta}$. Further, as in the data we assume a fixed $\operatorname{cost} \kappa_{i}^{\theta}$.

Entry costs for the creation of banks are denoted by $\Upsilon^{b} \geq \Upsilon^{f} \geq 0$. Every period a large number of potential entrants make the decision of whether or not to enter the market. Entry costs correspond to the initial injection of equity into the bank by its owner. An injection of equity would never be optimal for our one period lived consumers because they do not benefit from the charter value of the bank. For this reason, and to keep the model tractable, we assume that banks are owned by infinitely lived risk-neutral investors who discount the future at rate $\beta$ and have a large endowment (i.e. they have "deep pockets" and do not face any borrowing constraint). Investors choose the number of shares to buy in each bank

\footnotetext{
${ }^{12}$ Our previous paper [12] considers the more complex case of multiple dominant banks.
} 
(incumbent and newly created) to maximize their expected sum of present discounted value of current and future cash flows. We abstract from agency problems, so the objective of the individual bank is aligned with that of investors, i.e. they maximize the expected discounted sum of dividends and discount the future at rate $\beta$.

Let $\pi_{i, t+1}^{\theta}$ denote the end-of-period profits (i.e. after the realization of $z_{t+1}$ ) of bank $i$ of type $\theta$ as a function of its loans $\ell_{i, t}^{\theta}$, deposits $d_{i, t}^{\theta}$ and securities $a_{i, t+1}^{\theta}$ given by

$\pi_{i, t+1}^{\theta}=\left\{p\left(R_{t}, z_{t+1}\right)\left(1+r_{t}^{L}\right)+\left(1-p\left(R, z_{t+1}\right)\right)(1-\lambda)\right\} \ell_{i, t}^{\theta}+r_{t}^{a} a_{i, t+1}^{\theta}-\left(1+r_{t}^{D}\right) d_{i, t}^{\theta}-\left\{\kappa_{i}^{\theta}+c_{i}^{\theta} \ell_{i, t}^{\theta}\right\}$.

The first two terms represent the gross return the bank receives from successful and unsuccessful loan projects respectively, the third term represents returns on securities, the fourth represents interest expenses (payments on deposits), and the fifth represents non-interest expenses.

After loan, deposit, and asset decisions have been made at the beginning of the period, we can define bank equity capital $e_{i, t}^{\theta}$ as

$$
e_{i, t}^{\theta} \equiv \underbrace{a_{i, t+1}^{\theta}+\ell_{i, t}^{\theta}}_{\text {assets }}-\underbrace{d_{i, t}^{\theta}}_{\text {liabilities }} .
$$

If banks face a capital requirement, they are forced to maintain a level of equity that is at least a fraction $\varphi^{\theta}$ of risk weighted assets (with weight $w$ on the risk free asset). Thus, banks face the following constraint

$$
e_{i, t}^{\theta} \geq \varphi^{\theta}\left(\ell_{i, t}^{\theta}+w a_{i, t+1}^{\theta}\right) \Rightarrow \ell_{i, t}^{\theta}\left(1-\varphi^{\theta}\right)+a_{i, t+1}^{\theta}\left(1-w \varphi^{\theta}\right)-d_{i, t}^{\theta} \geq 0 .
$$

If $w$ is small, as called for in the BIS Basel Accord, then it is easier to satisfy the capital requirement the higher is $a_{i, t+1}^{\theta}$ and the lower is $\varphi^{\theta}$. Securities relax the capital requirement constraint but also affect the feasibility condition of a bank. This creates room for a precautionary motive for net securities and the possibility that banks hold capital equity above the level required by the regulatory authority. ${ }^{13}$

Following the realization of $z_{t+1}$, bank $i$ of type $\theta$ can either borrow short term to finance cash flow deficiencies or store its cash until next period. Specifically, denote short term borrowings by $B_{i, t+1}^{\theta}>0$ and cash storage by $B_{i, t+1}^{\theta}<0$. The net rate at which banks

\footnotetext{
${ }^{13}$ Another policy proposal is associated with bank liquidity requirements. Basel III [5] proposed that the liquidity coverage ratio, which is the stock of high-quality liquid assets (which include government securities) divided by total net cash outflows over the next 30 calendar days, should exceed $100 \%$. In the context of a model period being one year, this would amount to a critical value of $1 / 12$ or roughly $8 \%$. This is also close to the figure for reserve requirements which is bank size dependent, anywhere from zero to $10 \%$. Since reserves now pay interest, bank liquidity requirements are similar in nature to current reserve requirement policy in our model. For the model, we assume

$$
\gamma^{\theta} d_{i, t}^{\theta} \leq a_{i, t+1}^{\theta}
$$

where $\gamma^{\theta}$ denotes the (possibly) size dependent liquidity requirement.
} 
borrow or store is denoted $r_{t}^{B}\left(B_{i, t+1}\right)$. For instance, if the bank chooses to hold cash over to the next period, then $r_{t}^{B}\left(B_{i, t+1}\right)=0$.

Bank borrowing must be repaid at the beginning of the next period, before any other actions are taken. We assume that borrowing is subject to a collateral constraint: ${ }^{14}$

$$
B_{i, t+1}^{\theta} \leq \frac{a_{i, t+1}^{\theta}}{\left(1+r_{t}^{B}\right)}
$$

Repurchase agreements are an example of collateralized short term borrowing, while federal funds borrowing is unsecured. This implies that beginning-of-next-period cash and securities holdings are given by

$$
\tilde{a}_{i, t+1}^{\theta}=a_{i, t+1}^{\theta}-\left(1+r_{t}^{B}\right) \cdot B_{i, t+1}^{\theta} \geq 0 .
$$

Bank dividends at the end of the period are

$$
\mathcal{D}_{i, t+1}^{\theta}=\pi_{i, t+1}^{\theta}+B_{i, t+1}^{\theta} \geq 0
$$

which are constrained to be positive since we assume that new equity financing is prohibitively expensive. A bank with positive cash flow $\pi_{t+1}^{\theta}>0$ which chooses to pay that cash flow as dividends, chooses $B_{i, t+1}^{\theta}=0$ otherwise it can lend or store cash $B_{i, t+1}^{\theta}<0$ thereby raising beginning-of-next period's assets. A bank with negative cash flow $\pi_{t+1}^{\theta}<0$ can borrow $B_{i, t+1}^{\theta}>0$ against assets to avoid exit but beginning-of-next-period assets will fall.

There is limited liability on the part of banks. This imposes a lower bound equal to zero in the case that the bank exits. In the context of our model, limited liability implies that upon exit, the bank gets:

$$
\begin{array}{r}
\max \left\{\xi \left[\left\{p\left(R_{t}, z_{t+1}\right)\left(1+r_{t}^{L}\right)+\left(1-p\left(R, z_{t+1}\right)\right)(1-\lambda)-c_{i}^{\theta}\right\} \ell_{i, t}^{\theta}\right.\right. \\
\left.\left.+\left(1+r_{t}^{a}\right) a_{i, t+1}^{\theta}\right]-d_{i, t}^{\theta}\left(1+r_{t}^{D}\right)-\kappa^{\theta}, 0\right\}
\end{array}
$$

where $\xi \in[0,1]$ measures liquidation costs in the event of exit.

The fact that $a_{i, t+1}^{\theta} \in \mathbb{R}_{+}$, the capital requirement constraint (5), the collateral constraint (7), and limited limited liability (10) combine to imply that there exists a value of net securities $\underline{a}$ such that if $\tilde{a}_{i, t}^{\theta}<\underline{a}$ the only feasible option for the bank is to exit. ${ }^{15}$ Thus, in

\footnotetext{
${ }^{14}$ Along with limited liability, the collateral constraint can arise as a consequence of a commitment problem as in Gertler and Kiyotaki [21].

${ }^{15}$ To see this, for simplicity, consider the case where $\tilde{a}_{i, t}^{\theta}=0$. Then, given that there is no positive value of loans that satisfies the capital requirement constraint and that in general $r^{a} \geq r^{D}$, the bank will choose $a_{i, t+1}^{\theta}=d_{i, t}^{\theta}$. The continuation value of profits are $\pi_{i, t+1}^{\theta}=r_{t}^{a} a_{i, t+1}^{\theta}-\left(1+r_{t}^{\bar{D}}\right) d_{i, t}^{\theta}-\kappa^{\theta}<0$ as long as $\kappa^{\theta} \geq d_{i, t}^{\theta}\left(r_{t}^{a}-r_{t}^{D}-1\right)$. But $\kappa^{\theta} \geq d_{i, t}^{\theta}\left(r_{t}^{a}-r_{t}^{D}-1\right)$ holds since $\left(r_{t}^{a}-r_{t}^{D}-1\right)<1$ for reasonable parameter values. The bank could cover the negative profits with borrowings, that is using $B_{i, t+1}^{\theta}=\left(1+r_{t}^{D}-r_{t}^{a}\right) d_{i, t}^{\theta}+\kappa^{\theta}$, but since $B_{i, t+1}^{\theta}\left(1+r_{t}^{B}\right) \leq a_{i, t+1}^{\theta}=d_{i, t}^{\theta}$ has to hold, this option is not feasible. Thus, continuing is not a feasible option when assets are below a certain low threshold.
} 
order to avoid exit due to what amounts to an empty constraint set, any bank must hold (at least) a small amount of net securities.

We denote the industry state by

$$
\zeta_{t}=\left\{\zeta_{t}^{b}(\tilde{a}, \delta), \zeta_{t}^{f}(\tilde{a}, \delta)\right\}
$$

where each element of $\zeta_{t}$ is a measure $\zeta_{t}^{\theta}(\tilde{a}, \delta)$ corresponding to active banks of type $\theta$ over matched deposits $\delta$ and net assets $\tilde{a}$. It should be understood that $\zeta_{t}^{b}(\tilde{a}, \delta)$ is a counting measure which simply assigns one to the asset level and deposit constraint of the big bank.

\subsection{Information}

There is asymmetric information on the part of borrowers and lenders. Only borrowers know the riskiness of the project they choose $\left(R_{t}\right)$ and their outside option $\left(\omega_{t}\right)$. All other information (e.g. project success or failure) is observable.

\subsection{Timing}

At the beginning of period $t$,

1. Liquidity shocks $\delta_{t}$ are realized.

2. Given the beginning of period state $\left(\zeta_{t}, z_{t}\right)$, borrowers draw $\omega_{t}$.

3. The dominant bank chooses how many loans to extend, how many deposits to accept given depositors choices, and how many assets to hold $\left(\ell_{i, t}^{b}, d_{i, t}^{b}, a_{i, t+1}^{b}\right)$.

4. Each fringe bank observes the total loan supply of the dominant bank $\left(\ell_{i, t}^{b}\right)$ and all other fringe banks (that jointly determine the loan interest rate $r_{t}^{L}$ ) and simultaneously decide how many loans to extend, deposits to accept, and how many assets to hold $\left(\ell_{i, t}^{f}, d_{i, t}^{f}, a_{i, t+1}^{f}\right)$. Borrowers choose whether or not to undertake a project, and if so a level of technology $R_{t}$.

5. Aggregate return shocks $z_{t+1}$ are realized, as well as idiosyncratic project success shocks.

6. Banks choose whether to borrow short term $\left(B_{i, t+1}^{\theta}\right)$ and dividend policy. Exit and entry decisions are made in that order.

7. Households pay taxes $\tau_{t+1}$ to fund deposit insurance and consume.

\section{Industry Equilibrium}

Since we will use recursive methods to define an equilibrium, let any variable $n_{t}$ be denoted $n$ and $n_{t+1}$ be denoted $n^{\prime}$. 


\subsection{Borrower Decision Making}

Starting in state $z$, borrowers take the loan interest rate $r^{L}$ as given and choose whether to demand a loan and if so, what technology $R$ to operate. Specifically, if a borrower chooses to participate, then given limited liability his problem is to solve:

$$
v\left(r^{L}, z\right)=\max _{R} E_{z^{\prime} \mid z}\left[p\left(R, z^{\prime}\right)\left(z^{\prime} R-r^{L}\right)\right] .
$$

Let $R\left(r^{L}, z\right)$ denote the borrower's decision rule that solves (12). We assume that the necessary and sufficient conditions for this problem to be well behaved are satisfied. The borrower chooses to demand a loan if

$$
v\left(r^{L}, z\right) \geq \omega .
$$

In an interior solution, the first order condition is given by

$$
E_{z^{\prime} \mid z}\{\underbrace{p\left(R, z^{\prime}\right) z^{\prime}}_{(+)}+\underbrace{\frac{\partial p\left(R, z^{\prime}\right)}{\partial R}}_{(-)}\left[z^{\prime} R-r^{L}\right]\}=0
$$

The first term is the benefit of choosing a higher return project while the second term is the cost associated with the increased risk of failure.

To understand how bank lending rates influence the borrower's choice of risky projects, one can totally differentiate (14) with respect to $r^{L}$ and re-arrange to yield

$$
\frac{d R^{*}}{d r^{L}}=\frac{E_{z^{\prime} \mid z}\left[\frac{\partial p\left(R^{*}, z^{\prime}\right)}{\partial R^{*}}\right]}{E_{z^{\prime} \mid z}\left\{\frac{\partial^{2} p\left(R^{*}, z^{\prime}\right)}{\left(\partial R^{*}\right)^{2}}\left[z^{\prime} R^{*}-r^{L}\right]+2 \frac{\partial p\left(R^{*}, z^{\prime}\right)}{\partial R^{*}} z^{\prime}\right\}}>0
$$

where $R^{*}=R\left(r^{L}, z\right)$. Since both the numerator and the denominator are strictly negative (the denominator is negative by virtue of the sufficient conditions), a higher borrowing rate implies the borrower takes on more risk. Boyd and De Nicolo [9] call $\frac{d R^{*}}{d r^{L}}>0$ in (15) the "risk shifting effect". Risk neutrality and limited liability are important for this result.

An application of the envelope theorem implies

$$
\frac{\partial v\left(r^{L}, z\right)}{\partial r^{L}}=-E_{z^{\prime} \mid z}\left[p\left(R, z^{\prime}\right)\right]<0 .
$$

Thus, participating borrowers are worse off the higher are borrowing rates. This has implications for the demand for loans determined by the participation constraint. In particular, since the demand for loans is given by

$$
L^{d}\left(r^{L}, z\right)=N \cdot \int_{\underline{\omega}}^{\bar{\omega}} 1_{\left\{\omega \leq v\left(r^{L}, z\right)\right\}} d \Omega(\omega),
$$

then (16) implies $\frac{\partial L^{d}\left(r^{L}, z\right)}{\partial r^{L}}<0$. 


\subsection{Depositor Decision Making}

If $r^{D}=\bar{r}$, then a household would be indifferent between matching with a bank and using the autarkic storage technology so we can assign such households to a bank. If it is to match directly with a borrower, the depositor must compete with banks for the borrower. Hence, in successful states, the household cannot expect to receive more than the bank lending rate $r^{L}$ but of course could choose to make a take-it-or-leave-it offer of their unit of a good for a return $\widehat{r}<r^{L}$ and hence entice a borrower to match with them rather than a bank. Given state contingent taxes $\tau\left(\zeta, z, z^{\prime}\right)$, the household matches with a bank if possible and strictly decides to remain in autarky otherwise provided

$$
\begin{aligned}
U \equiv \quad & E_{z^{\prime} \mid z}\left[u\left(1+\bar{r}-\tau\left(\zeta, z, z^{\prime}\right)\right)\right]> \\
& \max _{\widehat{r}<r^{L}} E_{z^{\prime} \mid z}\left[p\left(\widehat{R}, z^{\prime}\right) u\left(1+\widehat{r}-\tau\left(\zeta, z, z^{\prime}\right)\right)\right. \\
& \left.+\left(1-p\left(\widehat{R}, z^{\prime}\right)\right) u\left(1-\lambda-\tau\left(\zeta, z, z^{\prime}\right)\right)\right] \equiv U^{E}
\end{aligned}
$$

Condition (18) makes clear the reason for a bank in our environment. By matching with a large number of borrowers, the bank can diversify the risk of project failure and this is valuable to risk averse households. It is the loan side uncertainty counterpart of a bank in Diamond and Dybvig [14].

If this condition is satisfied, then the total supply of deposits is given by

$$
D^{s}=d^{b}(\tilde{a}, \delta, z, \zeta)+\int d^{f}(\tilde{a}, \delta, z, \zeta) \zeta^{f}(d \tilde{a}, d \delta) \leq H
$$

\subsection{Incumbent Bank Decision Making}

After being matched with $\delta$ deposits, an incumbent bank $i$ of type $\theta$ chooses loans $\ell_{i}^{\theta}$, deposits $d_{i}^{\theta}$, and asset holdings $a_{i}^{\theta^{\prime}}$ in order to maximize expected discounted dividends/cash flows. We assume Cournot competition in the loan market. Following the realization of $z^{\prime}$, banks can choose to borrow or store $B_{i}^{\prime} \theta$ and whether to exit $x_{i}(\theta)$.

Let $\sigma_{-i}$ denote the industry state dependent balance sheet, exit, and entry strategies of all other banks. Given the Cournot assumption, the big bank takes into account that it affects the loan interest rate and its loan supply affects the total supply of loans by fringe banks. Differentiating the bank profit function $\pi_{i}^{\theta}$ defined in (3) with respect to $\ell_{i}^{\theta}$ we obtain

$$
\frac{d \pi_{i}^{\theta}}{d \ell_{i}^{\theta}}=[\underbrace{p r^{L}-(1-p) \lambda-c^{\theta}}_{(+) \text {or }(-)}]+\ell_{i}^{\theta}[\underbrace{p}_{(+)}+\underbrace{\frac{\partial p}{\partial R} \frac{\partial R}{\partial r^{L}}\left(r^{L}+\lambda\right)}_{(-)}] \underbrace{\frac{d r^{L}}{d \ell_{i}^{\theta}}}_{(-)} .
$$

The first bracket represents the marginal change in profits from extending an extra unit of loans. The second bracket corresponds to the marginal change in profits due to a bank's 
influence on the interest rate it faces. This term will reflect the bank's market power; for dominant banks $\frac{d r^{L}}{d \ell_{i}^{b}}<0$ while for fringe banks $\frac{d r^{L, j}}{d \ell_{i}^{f}}=0$.

Let the total supply of loans by fringe banks as a function of the aggregate state and the amount of loans that the big bank makes $\ell^{b}$ be given by

$$
L^{f}\left(\zeta, \ell^{b}\right)=\int \ell_{i}^{f}\left(\tilde{a}, \delta, \zeta, \ell^{b}\right) \zeta^{f}(d \tilde{a}, d \delta)
$$

The loan supply of fringe banks is a function of $\ell^{b}$ because fringe banks move after the big bank.

The value of a big bank at the beginning of the period but after overnight borrowing has been paid is:

$$
V^{b}(\tilde{a}, \delta, z, \zeta)=\max _{\ell \geq 0, d \in[0, \delta], a^{\prime} \geq \gamma^{b} d} \beta E_{z^{\prime} \mid z} W^{b}\left(\ell, d, a^{\prime}, \delta, \zeta, z^{\prime}\right)
$$

s.t.

$$
\begin{array}{r}
\tilde{a}+d \geq a^{\prime}+\ell \\
\ell\left(1-\varphi^{b}\right)+a^{\prime}\left(1-w \varphi^{b}\right)-d \geq 0 \\
\ell+L^{f}(\zeta, \ell)=L^{d}\left(r^{L}, z\right)
\end{array}
$$

where $W^{b}\left(\ell, d, a^{\prime}, \zeta, z^{\prime}\right)$ is the value of the bank at the end of the period for given loans $\ell$, deposits $d$, net securities $a^{\prime}$, and realized shocks. Equation (25) is the market clearing condition which is included since the dominant bank must take into account its impact on prices. Changes in $\ell$ affect the equilibrium interest rate through its direct effect on the aggregate loan supply (first term) but also through the effect on the loan supply of fringe banks (second term). For any given $\zeta, L^{f}(\zeta, \ell)$ can be thought of as a "reaction function" of fringe banks to the loan supply decision of the dominant bank.

The end-of-period function (that determines if the bank continues or exits and its future net securities position) is given by

$$
W^{b}\left(\ell, d, a^{\prime}, \delta, \zeta, z^{\prime}\right)=\max _{x \in\{0,1\}}\left\{W^{b, x=0}\left(\ell, d, a^{\prime}, \delta, \zeta, z^{\prime}\right), W^{b, x=1}\left(\ell, d, a^{\prime}, \delta, \zeta, z^{\prime}\right)\right\}
$$

where

$$
W^{b, x=0}\left(\ell, d, a^{\prime}, \delta, \zeta, z^{\prime}\right)=\max _{B^{\prime} \leq \frac{a^{\prime}}{\left(1+r^{B}\right)}}\left\{\pi^{b}\left(\ell, d, a^{\prime}, \zeta, z^{\prime}\right)+B^{\prime}+E_{\delta^{\prime} \mid \delta}^{b} V^{b}\left(\tilde{a}^{\prime}, \delta^{\prime}, z^{\prime}, \zeta^{\prime}\right)\right\}
$$

s.t.

$$
\begin{array}{r}
\tilde{a}^{\prime}=a^{\prime}-\left(1+r^{B}\right) B^{\prime} \geq 0 \\
\pi^{b}\left(\ell, d, a^{\prime}, \zeta, z^{\prime}\right)+B^{\prime} \geq 0 \\
\zeta^{\prime}=H\left(z, z^{\prime}, \zeta\right)
\end{array}
$$


where $E_{\delta^{\prime} \mid \delta}^{b}$ is the conditional expectation of future liquidity shocks for a big bank (i.e. based on the transition function $G^{b}\left(\delta^{\prime}, \delta\right)$ ). If the non-negativity of dividends constraint (29) is violated, we set $W^{b, x=0}\left(\ell, d, a^{\prime}, \zeta, \delta, z^{\prime}\right)=-\infty$ since we assume that banks have access to external funds only through $B$. In this case a bank that cannot borrow enough to stay afloat will exit. Equation (30) corresponds to the evolution of the aggregate state.

The value of exit is

$$
\begin{array}{r}
W^{b, x=1}\left(\ell, d, a^{\prime}, \delta, \zeta, z^{\prime}\right)=\max \left\{\xi \left[\left\{p\left(R, z^{\prime}\right)\left(1+r^{L}\right)+\left(1-p\left(R, z^{\prime}\right)\right)(1-\lambda)-c^{b}\right\} \ell\right.\right. \\
\left.\left.+\left(1+r^{a}\right) a^{\prime}\right]-d\left(1+r^{D}\right)-\kappa^{b}, 0\right\}
\end{array}
$$

The lower bound on the exit value is associated with limited liability.

The solution to problem (22)-(31) provides big bank decision rules $\ell^{b}(\tilde{a}, \delta, z, \zeta), a^{b^{\prime}}(\tilde{a}, \delta, z, \zeta)$, $d^{b}(\tilde{a}, \delta, z, \zeta), B^{b^{\prime}}\left(\ell, d, a^{\prime}, \delta, z^{\prime}, \zeta\right), x^{b}\left(\ell, d, a^{\prime}, \delta, \zeta, z^{\prime}\right)$ as well as value functions.

Next we turn to the fringe bank problem. The fringe bank takes as given the aggregate loan supply (and thus the interest rate). The value of a fringe bank at the beginning of the period but after any borrowings or dividends have been paid is:

$$
V^{f}(\tilde{a}, \delta, z, \zeta)=\max _{\ell \geq 0, d \in[0, \delta], a^{\prime} \geq \gamma^{f} d} \beta E_{z^{\prime} \mid z} W^{f}\left(\ell, d, a^{\prime}, \delta, \zeta, z^{\prime}\right),
$$

s.t.

$$
\begin{array}{r}
\tilde{a}+d \geq a^{\prime}+\ell \\
\ell\left(1-\varphi^{f}\right)+a^{\prime}\left(1-w \varphi^{f}\right)-d \geq 0 \\
\ell^{b}(\zeta)+L^{f}\left(\zeta, \ell^{b}(\zeta)\right)=L^{d}\left(r^{L}, z\right)
\end{array}
$$

where $W^{f}\left(\ell, d, a^{\prime}, \zeta, \delta, z^{\prime}\right)$ is the value of the bank at the end of the period for given loans $\ell$, deposits $d$, net securities $a^{\prime}$, and realized shocks. Even though fringe banks take the loan interest rate as given, that rate is determined by the solution to equation (35) which incorporates the loan decision rule of the big bank. The solution to this problem provides $\ell^{f}(a, \delta, z, \zeta), d^{f}(a, \delta, z, \zeta)$ and $a^{\prime} f(a, \delta, z, \zeta)$.

The end of period function is given by

$$
W^{f}\left(\ell, d, a^{\prime}, \delta, \zeta, z^{\prime}\right)=\max _{x \in\{0,1\}}\left\{W^{f, x=0}\left(\ell, d, a^{\prime}, \delta, \zeta, z^{\prime}\right), W^{f, x=1}\left(\ell, d, a^{\prime}, \delta, \zeta, z^{\prime}\right)\right\}
$$

where

$$
W^{f, x=0}\left(\ell, d, a^{\prime}, \delta, \zeta, z^{\prime}\right)=\max _{B^{\prime} \leq \frac{a^{\prime}}{\left(1+r^{B}\right)}}\left\{\pi^{f}\left(\ell, d, a^{\prime}, \zeta, z^{\prime}\right)+B^{\prime}+E_{\delta^{\prime} \mid \delta}^{f} V^{f}\left(\tilde{a}^{\prime}, \delta^{\prime}, z^{\prime}, \zeta^{\prime}\right)\right\}
$$

s.t.

$$
\begin{array}{r}
\tilde{a}^{\prime}=a^{\prime}-\left(1+r^{B}\right) B^{\prime} \geq 0, \\
\pi^{f}\left(\ell, d, a^{\prime}, \zeta, z^{\prime}\right)+B^{\prime} \geq 0, \\
\zeta^{\prime}=H\left(z, z^{\prime}, \zeta\right) .
\end{array}
$$


As in the dominant bank case, if the non-negativity of dividends constraint (39) is violated, we set $W^{f, x=0}\left(\ell, d, a^{\prime}, \zeta, \delta, z^{\prime}\right)=-\infty$ since we assume that banks have access to external funds only through $B^{\prime}$. The value of exit is

$$
\begin{array}{r}
W^{f, x=1}\left(\ell, d, a^{\prime}, \delta, \zeta, z^{\prime}\right)=\max \left\{\xi \left[\left\{p\left(R, z^{\prime}\right)\left(1+r^{L}\right)+\left(1-p\left(R, z^{\prime}\right)\right)(1-\lambda)-c^{f}\right\} \ell\right.\right. \\
\left.\left.+\left(1+r^{a}\right) a^{\prime}\right]-d\left(1+r^{D}\right)-\kappa^{f}, 0\right\} .
\end{array}
$$

At the end of every period after the realization of $z^{\prime}$ and exit occurs, there is a large number of potential entrants of type $\theta$. In order to enter, they have to pay the entry cost $\Upsilon^{\theta}$ and decide on their initial level of securities $a^{\prime}$ (equal to initial bank equity capital since there are no other liabilities). The value of entry net of entry costs for banks of type $\theta$ is given by

$$
V^{\theta, e}\left(z, \zeta, z^{\prime}\right) \equiv \max _{a^{\prime}}\left\{-a^{\prime}+E_{\delta^{\prime}}^{\theta} V^{\theta}\left(a^{\prime}, \delta^{\prime}, z^{\prime}, H\left(z, \zeta, z^{\prime}\right)\right)\right\}-\Upsilon^{\theta}
$$

Potential entrants will decide to enter if $V^{\theta, e}\left(z, \zeta, z^{\prime}\right) \geq 0$. The argmax of equation (42) for those firms that enter defines the initial equity distribution of banks. ${ }^{16}$ Note that the new industry distribution is given by $\zeta^{\prime}=H\left(z, \zeta, z^{\prime}\right)$. The total number of entrants will be determined endogenously in equilibrium.

We denote by $E^{f}$ the mass of fringe entrants. Recall that, for simplicity, we assumed that there is at most one big active bank. Thus, the number of big bank entrants $E^{b}$ equals zero when there is an incumbent big bank and it is at most one when there is no active big bank in the market. In general, free entry implies that

$$
V^{\theta, e}\left(z, \zeta, z^{\prime}\right) \times E^{\theta}=0 .
$$

That is, in equilibrium, the value of entry is zero, the number of entrants is zero, or both.

\subsection{Evolution of the Cross-Sectional Bank Size Distribution}

The distribution of fringe banks evolves according to

$$
\zeta^{f^{\prime}}\left(a^{\prime}, \delta^{\prime}\right)=\int \sum_{\delta}\left(1-x^{f}(\cdot)\right) I_{\left.\left\{a^{\prime}=\tilde{a}^{f}(\cdot)\right)\right\}} G^{f}\left(\delta^{\prime}, \delta\right) d \zeta^{f}(a, \delta)+E^{f} \sum_{\delta} I_{\left.\left\{a^{\prime}=a^{f, e}(\cdot)\right)\right\}} G^{f, e}(\delta) .
$$

Equation (44) makes clear how the law of motion for the distribution of banks is affected by entry and exit decisions.

\footnotetext{
${ }^{16}$ Only initial equity offerings can be made, after which we assume seasoned equity offerings are prohibitively costly.
} 


\subsection{Funding Deposit Insurance}

Across all states $\left(\zeta, z, z^{\prime}\right)$, taxes must cover deposit insurance in the event of bank failure. Let post-liquidation net transfers be given by

$$
\Delta^{\theta}=\left(1+r^{D}\right) d^{\theta}-\xi\left[\left\{p\left(1+r^{L}\right)+(1-p)(1-\lambda)-c^{\theta}\right\} \ell^{\theta}+a^{\theta^{\prime}}\left(1+r^{a}\right)\right]
$$

where $\xi \leq 1$ is the post liquidation value of the bank's assets and cash flow. Then aggregate taxes are given by

$$
\tau\left(z, \zeta, z^{\prime}\right) \cdot \Xi=\int \sum_{\delta} x^{f} \max \left\{0, \Delta^{f}\right\} d \zeta^{f}(a, \delta)+x^{b} \max \left\{0, \Delta^{b}\right\} .
$$

\subsection{Definition of Equilibrium}

Given government policy parameters $\left(r^{a}, r^{B}, \varphi^{\theta}, w, \gamma^{\theta}\right)$, a pure strategy Markov Perfect Industry Equilibrium (MPIE) is a set of functions $\left\{v\left(r^{L}, z\right), R\left(r^{L}, z\right)\right\}$ describing borrower behavior, a set of functions $\left\{V_{i}^{\theta}, \ell_{i}^{\theta}, d_{i}^{\theta}, a_{i}^{\theta^{\prime}}, B_{i}^{\theta^{\prime}}, x_{i}^{\theta}, \chi_{i}^{\theta}\right\}$ describing bank behavior, a loan interest rate $r^{L}(\zeta, z)$, a deposit interest rate $r^{D}=\bar{r}$, an industry state $\zeta$, a function describing the number of entrants $E^{\theta}\left(z, \zeta, z^{\prime}\right)$, and a tax function $\tau\left(z, \zeta, z^{\prime}\right)$ such that:

1. Given a loan interest rate $r^{L}, v\left(r^{L}, z\right)$ and $R\left(r^{L}, z\right)$ are consistent with borrower optimization (12) and (13).

2. At $r^{D}=\bar{r}$, the household deposit participation constraint (18) is satisfied.

3. Given the loan demand function, $\left\{V^{\theta}, \ell^{\theta}, d^{\theta}, a_{i}^{\theta^{\prime}}, B_{i}^{\theta^{\prime}}, x^{\theta}, \chi^{\theta}\right\}$ are consistent with bank optimization (22)-(41).

4. The entry asset decision rules are consistent with bank optimization (42) and the free entry condition is satisfied (43).

5. The law of motion for the industry state (30) induces a sequence of cross-sectional distributions which are consistent with entry, exit, and asset decision rules in (44).

6. The interest rate $r^{L}(\zeta, z)$ is such that the loan market clears. That is,

$$
L^{d}\left(r^{L}, z\right)=\ell^{b}(\zeta)+L^{f}\left(\zeta, \ell^{b}(\zeta)\right)
$$

where aggregate loan demand $L^{d}\left(r^{L}, z\right)$ given by (17).

7. Across all states $\left(z, \zeta, z^{\prime}\right)$, taxes cover deposit insurance transfers in (45). 


\section{Calibration}

At this stage, we have not finished calibrating parameters. A model period is set to be one year.

We begin with the parameterization of the four stochastic processes: $F\left(z^{\prime}, z\right), G^{\theta}\left(\delta^{\prime}, \delta\right)$, $p\left(R, z^{\prime}\right)$, and $\Omega(\omega)$. To calibrate the stochastic process for aggregate technology shocks $F\left(z^{\prime}, z\right)$, we use the NBER recession dates and create a recession indicator. More specifically, for a given year, the recession indicator takes a value equal to one if two or more quarters in that year were dated as part of a recession. The correlation of this indicator with HP filtered GDP equals -0.87. Then, we identify years where the indicator equals one with our periods of $z=z_{b}$ and construct a transition matrix. In particular, the maximum likelihood estimate of $F_{k j}$, the $(j, k) t h$ element of the aggregate state transition matrix, is the ratio of the number of times the economy switched from state $j$ to state $k$ to the number of times the economy was observed to be in state $j$. We normalize the value of $z_{g}=1$ and choose $z_{b}$ to match the variance of detrended GDP.

We identify "big" banks with the top $1 \%$ banks (when sorted by assets) and the fringe banks with the bottom $99 \%$ of the bank asset distribution. As in Pakes and McGuire [27] we restrict the number of big banks by setting the entry cost to a prohibitively high number if the number of incumbents after entry and exit exceeds a given number. In our application, we choose one. That is there will be a representative big dominant bank and and a mass $E^{f}$ of potential fringe banks. We link loan supply from the model to data in the following way (this also applies to securities, deposits and parameters or functions that are expressed in levels like fixed costs, entry costs, etc.). The model delivers a loan supply $\ell^{b}(\tilde{a}, \delta, z, \zeta)$ given by

$$
\ell^{\theta}(\tilde{a}, \delta, z, \zeta)=\int \ell_{i}^{\theta}(\tilde{a}, \delta, z, \zeta) \zeta^{\theta}(\tilde{a}, \delta)(d i) \equiv w^{\theta}(\tilde{a}, \delta) \bar{\ell}^{\theta}(\tilde{a}, \delta, z, \zeta)
$$

where $w^{\theta}(\tilde{a}, \delta)$ is the relative fraction of banks of type $\theta$ with assets $\tilde{a}$ and matched deposits $\delta$. Hence, $\bar{\ell}(\tilde{a}, \delta, z, \zeta)$ is the "representative" or "average" loan supply by banks of type $\theta$ with assets $\tilde{a}$ and matched deposits $\delta$. Since we work under the assumption of a representative big bank, the relative mass $w^{\theta}(\tilde{a}, \delta)$ is not relevant for the determination of equilibrium. However, it is important when taking the model to the data. For example, the average loan supply by a big bank is $\ell^{b}(\tilde{a}, \delta, z, \zeta) / w^{b}(\tilde{a}, \delta)$. We set $w^{\theta}(\tilde{a}, \delta)$ using data from the distribution of banks. In particular, since we associate big banks with the top $1 \%$ banks and fringe banks with the bottom $99 \%$, we set $\int w^{b}(\tilde{a}, \delta) d \zeta^{b}(\tilde{a}, \delta)=1 \%$ and $\int w^{f}(\tilde{a}, \delta) d \zeta^{f}(\tilde{a}, \delta)=99 \%$.

We make the following assumptions when parameterizing the stochastic deposit matching process. We assume that the support of $\delta$ for big banks is large enough that the constraint never binds, so we do not need to estimate a process for it. On the other hand, the law of motion for the deposit matching technology for fringe banks is parameterized using our panel of commercial banks in the U.S. In particular, after controlling for firm and year fixed effects as well as a time trend, we estimate the following autoregressive process for log-deposits for bank $i$ in period $t$

$$
\log \left(\delta_{i t}\right)=\left(1-\rho_{d}\right) k_{0}+\rho_{d} \log \left(\delta_{i t-1}\right)+k_{1} t+k_{2} t^{2}+k_{3, t}+\gamma_{i}+u_{i t}
$$


where $t$ denotes a time trend, $k_{3, t}$ are year fixed effects, $\gamma_{i}$ are bank fixed effects and $u_{i t}$ is iid and distributed $N\left(0, \sigma_{u}^{2}\right) .{ }^{17}$ Since this is a dynamic model we use the method proposed by Arellano and Bond [4]. To keep the state space workable, we apply the method proposed by Tauchen [29] to obtain a finite state Markov representation $G^{f}\left(\delta^{\prime}, \delta\right)$ to the autoregressive process in (47). To apply Tauchen's method, we use the estimated values of $\rho_{d}=0.8415$ and $\sigma_{u}=0.1904$ from (47). Since we work with a normalization in the model (i.e. $z_{g}=1$ ), the mean $k_{0}$ in (47) is not directly relevant. Instead we choose to calibrate the mean of the finite state markov process, denoted $\mu_{d}$, to match the observed deposit market share of the fringe sector.

We parameterize the stochastic process for the borrower's project as follows. For each borrower, let $y=\alpha z^{\prime}+(1-\alpha) \varepsilon_{e}-b R^{\psi}$ where $\varepsilon_{e}$ is drawn from $N\left(\mu_{\varepsilon}, \sigma_{\varepsilon}^{2}\right)$. The borrower's idiosyncratic project uncertainty is iid across agents. We define success to be the event that $y>0$, so in states with higher $z$ or higher $\varepsilon_{e}$ success is more likely. Then

$$
\begin{aligned}
p\left(R, z^{\prime}\right) & =1-\operatorname{Pr}\left(y \leq 0 \mid R, z^{\prime}\right) \\
& =1-\operatorname{Pr}\left(\varepsilon_{e} \leq \frac{-\alpha z^{\prime}+b R^{\psi}}{(1-\alpha)}\right) \\
& =\Phi\left(\frac{\alpha z^{\prime}-b R^{\psi}}{(1-\alpha)}\right)
\end{aligned}
$$

where $\Phi(x)$ is a normal cumulative distribution function with mean $\mu_{\varepsilon}$ and variance $\sigma_{\varepsilon}^{2}$.

The stochastic process for borrower outside options, $\Omega(\omega)$, is simply taken to be the uniform distribution $[\underline{\omega}, \bar{\omega}]$ where $\underline{\omega}=0$.

We calibrate $\bar{r}=r^{D}$ using data from banks' balance sheets. We target the average cost of funds computed as the ratio of interest expense on funds (deposits and federal funds) over total deposits and federal funds for commercial banks in the US from 1976 to $2008 .{ }^{18}$ Similarly, we calibrate $r^{a}$ to the ratio of interest income from securities over the total securities.

Depositor preferences are given by $u(x)=\frac{x^{1-\sigma}}{1-\sigma}$ with $\sigma=2$, a standard value in the macro literature. At this level of risk aversion the depositor participation constraint is satisfied. The mass of borrowers is normalized to 1 .

We estimate the marginal cost of producing a loan $c^{\theta}$ and the fixed cost $\kappa^{\theta}$ using our panel of U.S. commercial banks following the empirical literature on banking (see for example Berger et. al. [6]). ${ }^{19}$ The value of $c^{\theta}$ is derived from the estimated marginal Net Non-interest Expenses that, in place, are defined to be Marginal Non-interest Expenses minus Marginal Non-interest Income. Marginal Non-interest Income is estimated as the ratio of total noninterest income over assets. Marginal Non-interest Expenses is derived from the following

\footnotetext{
${ }^{17}$ Note that since the problem of the fringe bank is linear, the solution to our problem implies that the capacity constraint binds in almost all cases and we can approximate the constraint using information on deposits.

${ }^{18}$ Source: FDIC, Call and Thrift Financial Reports, Balance Sheet and Income Statement (http://www2.fdic.gov/hsob/SelectRpt.asp?EntryTyp=10). The nominal interest rate is converted to a real interest rate by using the CPI.

${ }^{19}$ The cost structure estimated is also used to compute our measure of Markups and the Lerner Index.
} 
trans-log cost function:

$$
\begin{aligned}
\log \left(T_{i t}\right)= & a_{i}+k_{1} \log \left(w_{i t}^{1}\right)+h_{1} \log \left(\ell_{i t}\right)+k_{2} \log \left(y_{i t}\right)+k_{3} \log \left(w_{i t}^{1}\right)^{2} \\
& +h_{2}\left[\log \left(\ell_{i t}\right)\right]^{2}+k_{4}\left[\log \left(y_{i t}\right)\right]^{2}+h_{3} \log \left(\ell_{i t}\right) \log \left(y_{i t}\right)+h_{4} \log \left(\ell_{i t}\right) \log \left(w_{i t}^{1}\right) \\
& +k_{5} \log \left(y_{i t}\right) \log \left(w_{i t}^{1}\right)+k_{6} \log \left(x_{i t}\right)+\sum_{j=1,2} k_{7, j} t^{j}+k_{8, t}+\epsilon_{i t}
\end{aligned}
$$

where $T_{i t}$ is total non-interest expense minus expenses on premises and fixed assets, $w_{i t}^{1}$ corresponds to input prices (labor), $\ell_{i t}$ corresponds to real loans (one of the two bank $j$ 's output), $y_{i t}$ represents securities and other assets (the second bank output measured by real assets minus loans minus fixed assets minus cash), $x_{i t}$ is equity (a fixed netput), the $t$ regressor refers to a time trend and $k_{8, t}$ refer to time fixed effects. We estimate this equation by panel fixed effects with robust standard errors clustered by bank. Marginal non-interest expenses is then computed as:

$$
\frac{\partial T_{i t}}{\partial \ell_{i t}}=\frac{T_{i t}}{\ell_{i t}}\left[h_{1}+2 h_{2} \log \left(\ell_{i t}\right)+h_{3} \log \left(y_{i t}\right)+h_{4} \log \left(w_{i t}^{1}\right)\right]
$$

Finally, the fixed $\operatorname{cost} \kappa^{\theta}$ is estimated as the total cost on expenses of premises and fixed assets. We present the estimates of $\kappa^{\theta}$ scaled by total loans at the bank level. Table 3 shows the estimated parameters.

Table 3: Bank's Cost Structure

\begin{tabular}{l|cc|c|c}
\hline \hline Moment (\%) & Non-Int Inc. & Non-Int Exp. & Net Exp. $\left(c^{\theta}\right)$ & Fixed Cost $\left(\kappa^{\theta} / \ell^{\theta}\right)$ \\
\hline Top 1 \% Banks (\%) & $2.32^{\dagger}$ & $3.94^{\dagger}$ & $1.62^{\dagger}$ & $0.72^{\dagger}$ \\
Bottom 99 \% Banks (\%) & 0.89 & 2.48 & 1.60 & 0.99 \\
\hline \hline
\end{tabular}

Note: ${ }^{\dagger}$ Denotes statistically significant difference with Bottom $99 \%$ value. Data corresponds to commercial banks in the US. Source: FDIC, Call and Thrift Financial Reports. Net expense is calculated as Non-Interest Expense minus Non-Interest Income. Fixed cost $\kappa^{\theta}$ scaled by loans.

In our benchmark parametrization, we use values associated with current regulation. Thus we set the minimum level of bank equity risk-weighted capital ratio for both type of banks to $6 \%$. That is, $\varphi^{b}=\varphi^{f}=0.06$ and $w=0$.

We are left with fifteen parameters to estimate: $\left\{\alpha, b, \mu_{\varepsilon}, \sigma_{\varepsilon}, \psi, \mu_{d}, \lambda, \bar{\omega}, \beta, \xi, r^{B}, \kappa^{b}, \kappa^{f}, \Upsilon^{f}, \Upsilon^{b}\right\}$. We will estimate the parameters of the model by Simulated Method of Moments. Since we are interested in the standard errors of the parameters the number of moments needs to be larger than the number of parameters. Except for one data moment, we use the data for commercial banks described in Section 2 and in our companion paper. The extra moment the average real equity return (12.94\%) as reported by Diebold and Yilmaz [16] - is added to shed light on the borrower's return $R^{*}$. The set of targets from commercial bank data 
includes the average default frequency $(2.15 \%)$, the average entry rate $(1.60 \%)$, average loan return $(5.17 \%)$, average charge-off rate $(0.79 \%)$, the loan market share of Bottom $99 \%$ banks $(37.9 \%)$, the deposit market share of the Bottom $99 \%(35.56 \%)$, the capital ratio of the Bottom $99 \%$ banks (11.37\%), the capital ratio of the Top $1 \%$ banks $(7.5 \%)$, the securities to asset ratio of the bottom $99 \%$ banks $(20.75 \%$ ), the securities to asset ratio of the top $1 \%$ banks $(13.41 \%)$, fixed cost to loan ratio of the top $1 \%$ banks $(0.72 \%)$ and the fixed cost to loan ratio of the bottom $99 \%$ (0.99\%), the average loan markup (102.73\%), the ratio of profit rates of Top $1 \%$ banks to Bottom 99\% banks (63.79\%).

We use the following definitions to connect the model to the variables we presented in the data section.

Definition Model Moments

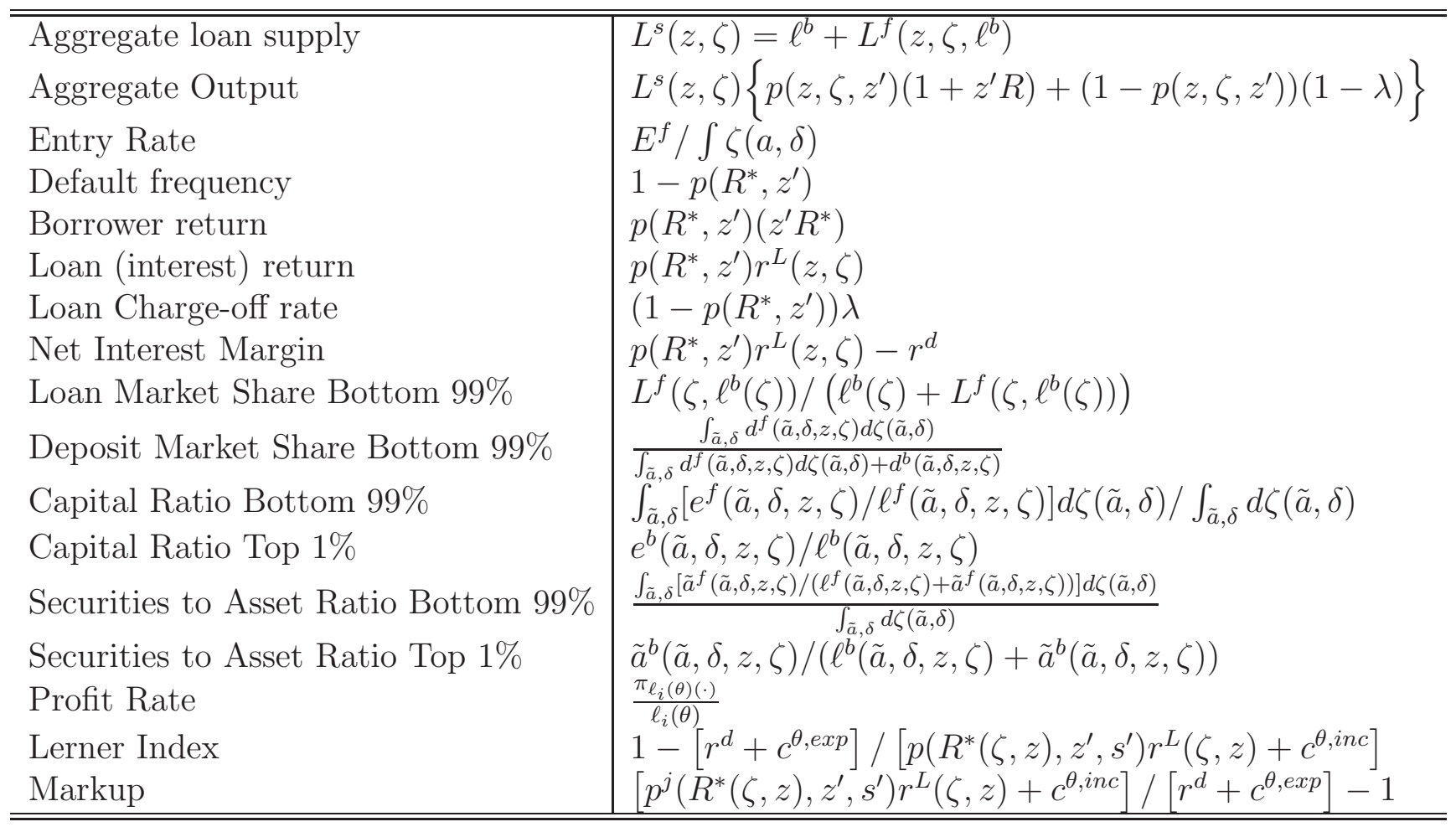

Table 4 shows the calibrated parameters. 
Table 4: Model Parameters

\begin{tabular}{l|c|c|l}
\hline \hline Parameter & & Value & Target \\
\hline Mass of borrowers & $B$ & 1 & Normalization \\
Mass of households & $\Xi$ & $B$ & Assumption \\
Dep. preferences & $\sigma$ & 2 & Part. constraint \\
Agg. shock in good state & $z_{g}$ & 1 & Normalization \\
Transition probability & $F\left(z_{g}, z_{g}\right)$ & 0.86 & NBER data \\
Transition probability & $F\left(z_{b}, z_{b}\right)$ & 0.43 & NBER data \\
Deposit interest rate (\%) & $\bar{r}=r^{d}$ & 0.86 & Int. expense \\
Net. non-int. exp. $n$ bank & $c^{b}$ & 1.62 & Net non-int exp. Top 1\% \\
Net. non-int. exp. $r$ bank & $c^{f}$ & 1.60 & Net non-int exp. bottom 99\% \\
Charge-off rate & $\lambda$ & 0.21 & Charge off rate \\
Autocorrel. Deposits & $\rho_{d}$ & 0.84 & Deposit Process Bottom 99\% \\
Std. Dev. Error & $\sigma_{u}$ & 0.19 & Deposit Process Bottom $99 \%$ \\
Securities Return (\%) & $r^{a}$ & 1.20 & Avg. Return Securities \\
Cost overnight funds & $r^{B}$ & 1.20 & Avg. Return Securities \\
Capital Requirement Top 1\% & $\left(\varphi^{b}, w\right)$ & $(4.0,0)$ & Basel II Capital Regulation \\
Capital Requirement Bottom $99 \%$ & $\left(\varphi^{f}, w\right)$ & $(4.0,0)$ & Basel II Capital Regulation \\
\hline Agg. shock in bad state & $z_{b}$ & 0.969 & Std. dev. Output \\
Weight agg. shock & $\alpha$ & 0.883 & Default freq. \\
Success prob. param. & $b$ & 3.773 & Loan interest return \\
Volatility borrower's dist. & $\sigma_{\epsilon}$ & 0.059 & Borrower Return \\
Success prob. param. & $\psi$ & 0.784 & Std. dev. net-int. margin \\
Mean Entrep. project Dist. & $\mu_{e}$ & -0.85 & Ratio Profits Top 1\% to bottom 99\% \\
Max. reservation value & $\bar{\omega}$ & 0.227 & Std. dev. Ls /Output \\
Discount Factor & $\beta$ & 0.95 & Sec. to asset ratio Bottom 99\% \\
Mean Deposits & $\mu_{d}$ & 0.04 & Deposit mkt share bottom 99\% \\
Fixed cost $b$ bank & $\kappa^{b}$ & 0.100 & Fixed cost over loans top 1\% \\
Fixed cost $f$ banks & $\kappa^{f}$ & 0.001 & Fixed cost over loans bottom $99 \%$ \\
Entry Cost $b$ bank & $\Upsilon^{b}$ & 0.050 & Entry accounted by top 1\% \\
Entry Cost $f$ banks & $\Upsilon^{f}$ & 0.006 & Bank entry rate \\
\hline \hline
\end{tabular}

The finite state Markov representation $G^{f}\left(\delta^{\prime}, \delta\right)$ obtained using the method proposed by Tauchen [29] and the estimated values of $\mu_{d}, \rho_{d}$ and $\sigma_{u}$ is:

$$
G^{f}\left(\delta^{\prime}, \delta\right)=\left[\begin{array}{ccccc}
0.632 & 0.353 & 0.014 & 0.000 & 0.000 \\
0.111 & 0.625 & 0.257 & 0.006 & 0.000 \\
0.002 & 0.175 & 0.645 & 0.175 & 0.003 \\
0.000 & 0.007 & 0.257 & 0.625 & 0.111 \\
0.000 & 0.000 & 0.014 & 0.353 & 0.637
\end{array}\right]
$$


and the corresponding grid is $\delta \in\{0.019,0.028,0.040,0.057,0.0 .081\}$. The distribution $G^{e, f}(\delta)$ is derived as the stationary distribution associated with $G^{f}\left(\delta^{\prime}, \delta\right)$.

Table 5 provides the moments generated by the model for the above parameter values relative to the data. Once again we note that the calibration is preliminary and so several model moments are relatively far from their targets.

Table 5: Model and Data Moments

\begin{tabular}{|c|c|c|}
\hline Moment (\%) & Model & $\overline{\text { Data }}$ \\
\hline Default Frequency & 2.69 & 2.15 \\
\hline Borrower Return & 12.33 & 12.94 \\
\hline Entry Rate & 1.55 & 1.60 \\
\hline Exit Rate & 1.55 & 1.65 \\
\hline Loan Int. Return & 6.58 & 5.17 \\
\hline Net Interest Margin & 5.69 & 5.08 \\
\hline Deposit Market Share Bottom 99\% & 29.25 & 35.56 \\
\hline Securities to Asset Ratio Bottom 99\% & 6.52 & 20.74 \\
\hline Fixed cost over loans top $1 \%$ & 0.95 & 0.72 \\
\hline Fixed cost over loans bottom $99 \%$ & 2.29 & 0.99 \\
\hline Ratio profit rate top $1 \%$ to bottom $99 \%$ & 99.98 & 63.79 \\
\hline Capital Ratio (risk-weighted) Top $1 \%^{\dagger}$ & 4.23 & 7.50 \\
\hline Capital Ratio (risk-weighted) $99 \%^{\dagger}$ & 13.10 & 11.37 \\
\hline Securities to Asset Ratio Top $1 \%^{\dagger}$ & 3.68 & 15.79 \\
\hline Avg. Loan Markup ${ }^{\dagger}$ & 111.19 & 102.73 \\
\hline Loan Market Share Bottom $99 \%^{\dagger}$ & 53.93 & 37.90 \\
\hline
\end{tabular}

Note: ${ }^{\dagger}$ Denotes non-targetted moment.

\section{$6 \quad$ Results}

For the parameter values in Table 4, we find an equilibrium where exit occurs along the equilibrium path by fringe banks with small to median deposit holdings and low asset levels (i.e. $\delta \leq \delta_{M}=0.04$ and $\tilde{a} \leq 0.004$ ) as well as fringe banks with bigger than median deposit holdings but even smaller asset levels (i.e. $\delta>\delta_{M}$ and $\tilde{a} \leq 0.002$ ) if the economy heads into bad times (i.e. $z=z_{g}$ and $\left.z^{\prime}=z_{b}\right){ }^{20}$ Dominant bank exit is not observed along the equilibrium path. On the equilibrium path, fringe banks that survive the arrival of a bad aggregate shock accumulate securities in order to avoid exit.

\footnotetext{
${ }^{20}$ We also find that fringe banks with low asset levels $(\tilde{a} \leq 0.013)$ exit if the economy stays in a recession (i.e. $z=z_{b}$ and $z^{\prime}=z_{b}$ ) but this is off-the-equilibrium path behavior.
} 


\subsection{Equilibrium Decision Rules}

To understand the equilibrium, we first describe borrower decisions. Figure 3 shows the borrower's optimal choice of project riskiness $R^{*}\left(r^{L}, z\right)$ and the inverse demand function associated with $L^{d}\left(r^{L}, z\right)$. The figure shows that the borrower's optimal project $R$ is an increasing function of the loan interest rate $r^{L}$. This is what Boyd and DeNicolo [9] call the "risk shifting" effect; that is, higher interest rates lead borrowers to choose more risky projects. Moreover, given that the value of the borrower is decreasing in $r^{L}$, aggregate loan demand is a decreasing function of $r^{L}$. The figure also illustrates that loan demand is pro-cyclical; that is, for a given interest rate, loan demand is higher in state $z_{g}$ than $z_{b}$.

Figure 3: Borrower Project and Inverse Loan Demand
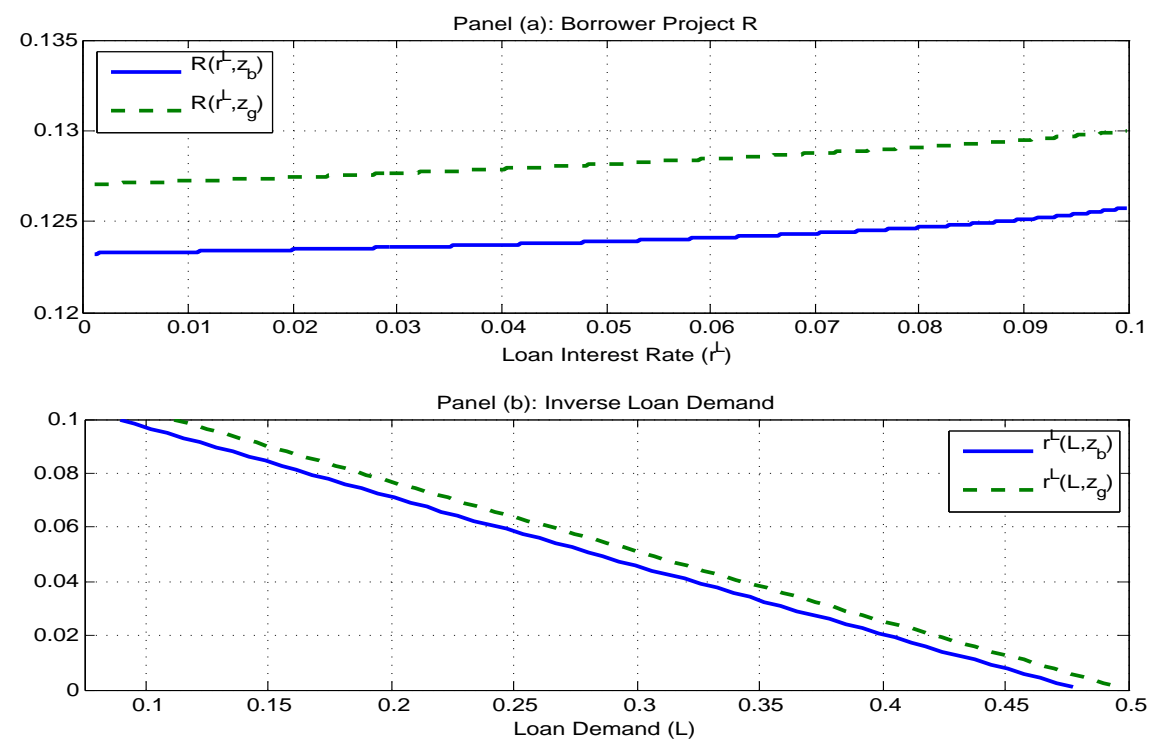

Next we turn to characterizing bank decision rules. Note that while these are equilibrium functions not every state is necessarily on-the-equilibrium path. It is best to work backwards and start with the exit decision rule. Since we find the big bank does not exit, we do not picture its decision rule. The fringe bank exit rule covers more of the state space as can be seen in Figure 4. Panel (i) graphs the smallest $\delta_{L}$ and largest $\delta_{H}$ fringe bank exit rules starting in the recession state $z_{b}$. With low assets, both types exit when the economy stays in a recession (off-the-equilibrium path). Panel (ii) shows that both small and large fringe banks exit when the economy transits from a boom to a recession if they have low assets. Notably, larger fringe banks are less likely than smaller ones to exit (i.e. their exit asset threshold is lower). 
Figure 4: Fringe Banks Exit Rule (for different values $\delta$ )
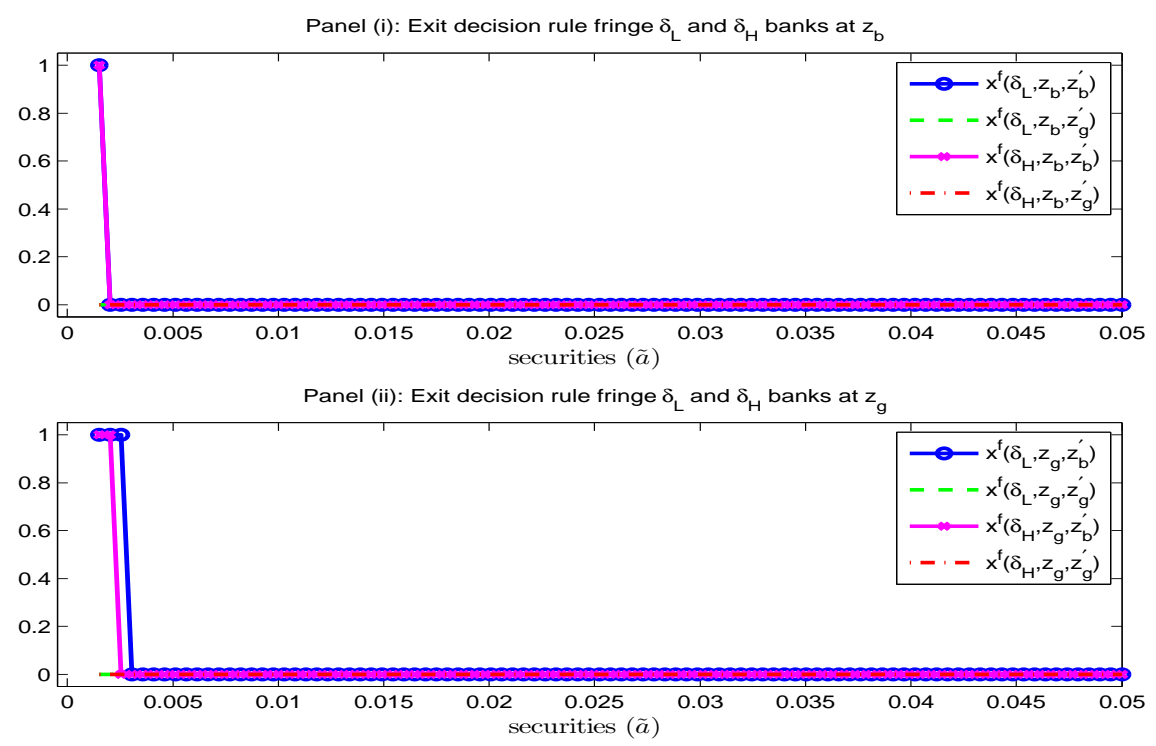

Banks try to start the next period with sufficient assets to avoid exit (since exit means the bank loses its charter value). In Figure 5 we plot beginning-of-next period's asset choices by the big bank and the median fringe bank (what we called $\tilde{a}_{i, t+1}^{\theta}$ in (8)). Note that the big bank augments future net assets at low current levels in all states except when the economy enters a recession from a boom. The latter arises because the big bank chooses to borrow in that state. The figure also shows that the median fringe bank is more likely to save at higher asset levels than a big bank. 
Figure 5: Big Bank and Median Fringe Bank Future Securities Rule $\tilde{a}^{\theta}$
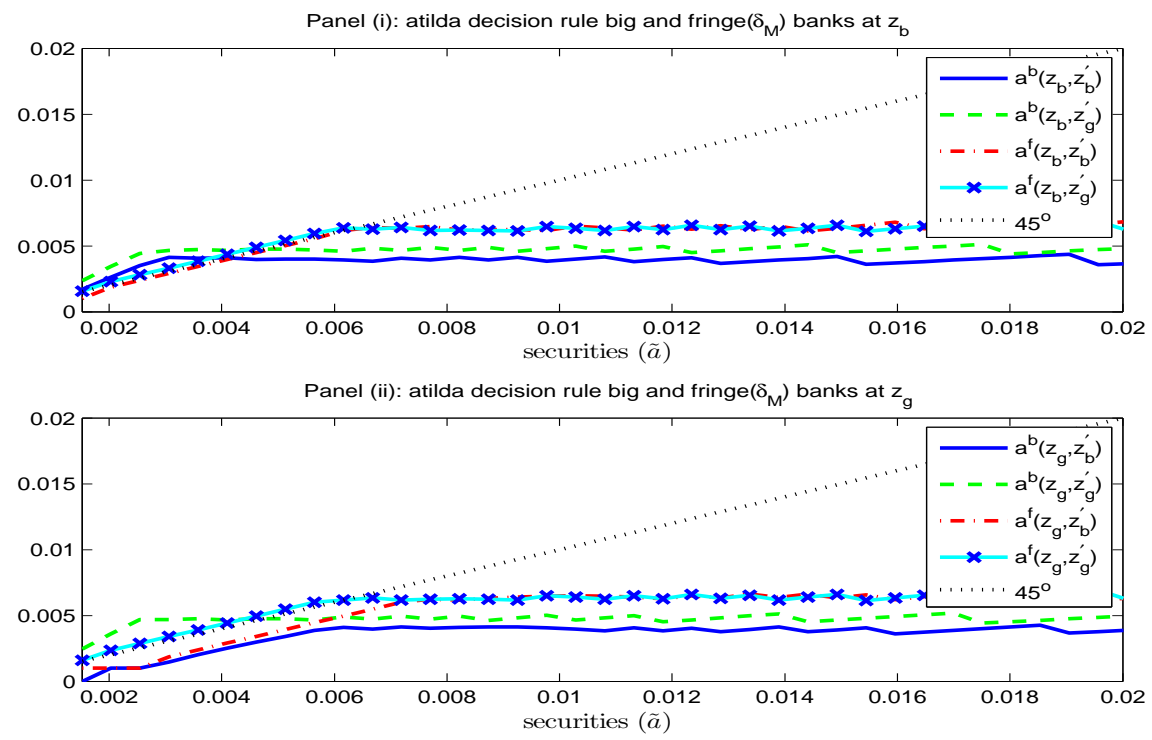

Figure 6 plots beginning-of-next period's asset choices by the smallest and largest fringe bank types. The figure shows that the smallest fringe bank is more constrained and unable to raise future securities like the largest fringe bank.

Figure 6: Fringe Banks Future Securities Rule $\tilde{a}^{\theta}$ (for different values $\delta$ )
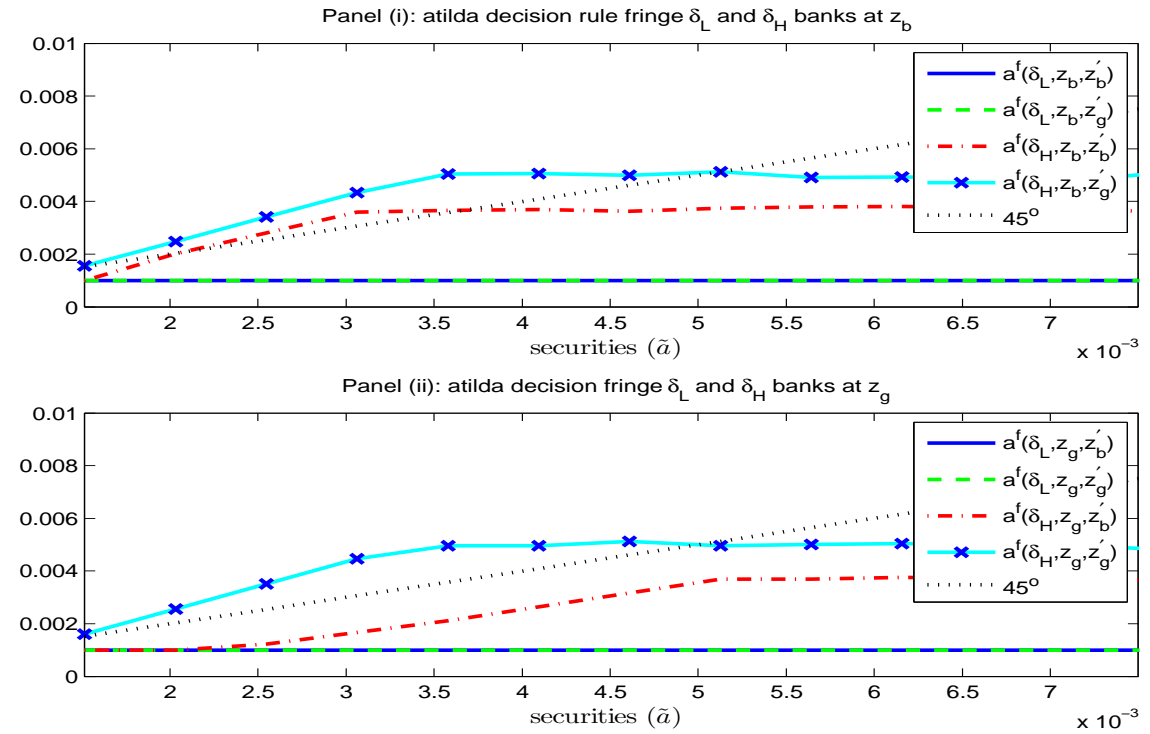
The big and median fringe bank borrowing decision rules are illustrated in Figure 7. It is evident from panel (ii) that both the big (at almost all asset levels) and fringe (at low asset levels) banks borrow when entering a recession from good times. At all other times the banks store cash and/or lend short term.

Figure 7: Big Bank and Median Fringe Bank Borrowing Rule $B^{\theta}$
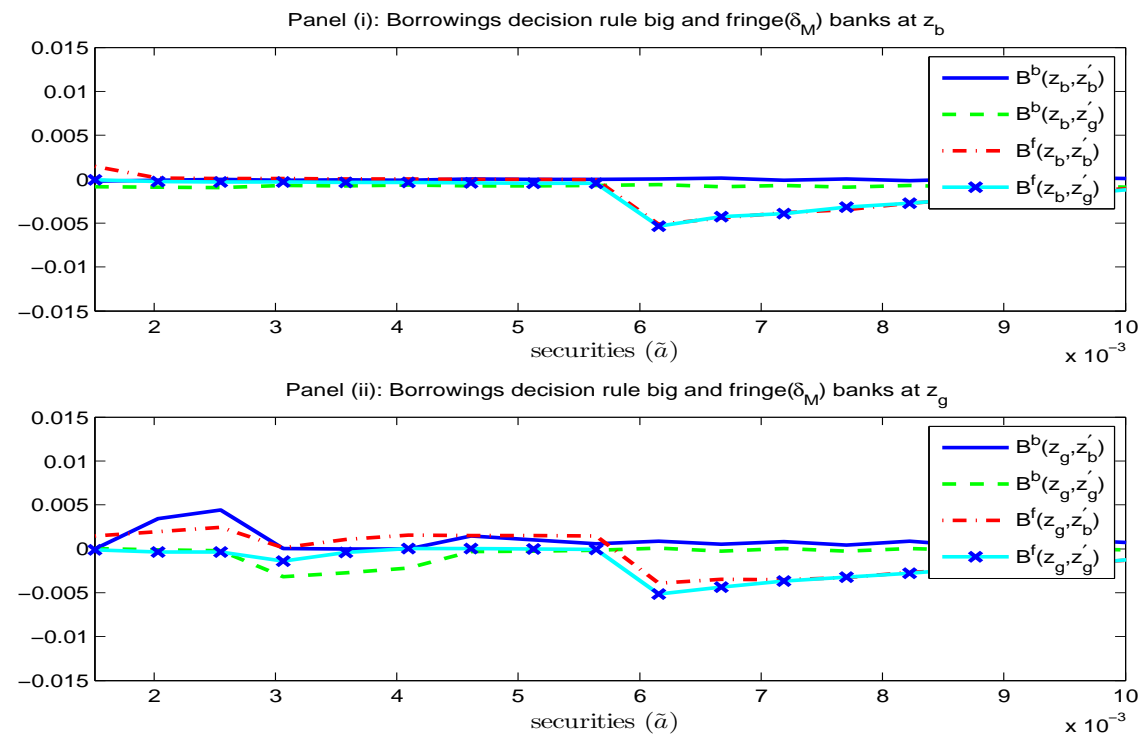

Figure (8) shows the borrowing decision rules for the smallest and largest fringe banks. As evident, both sizes of fringe bank store about the same amounts, except that the largest fringe stores significantly less as the economy enters a recession. 
Figure 8: Fringe Banks Borrowing Rule $B^{\theta}$ (for different values $\delta$ )
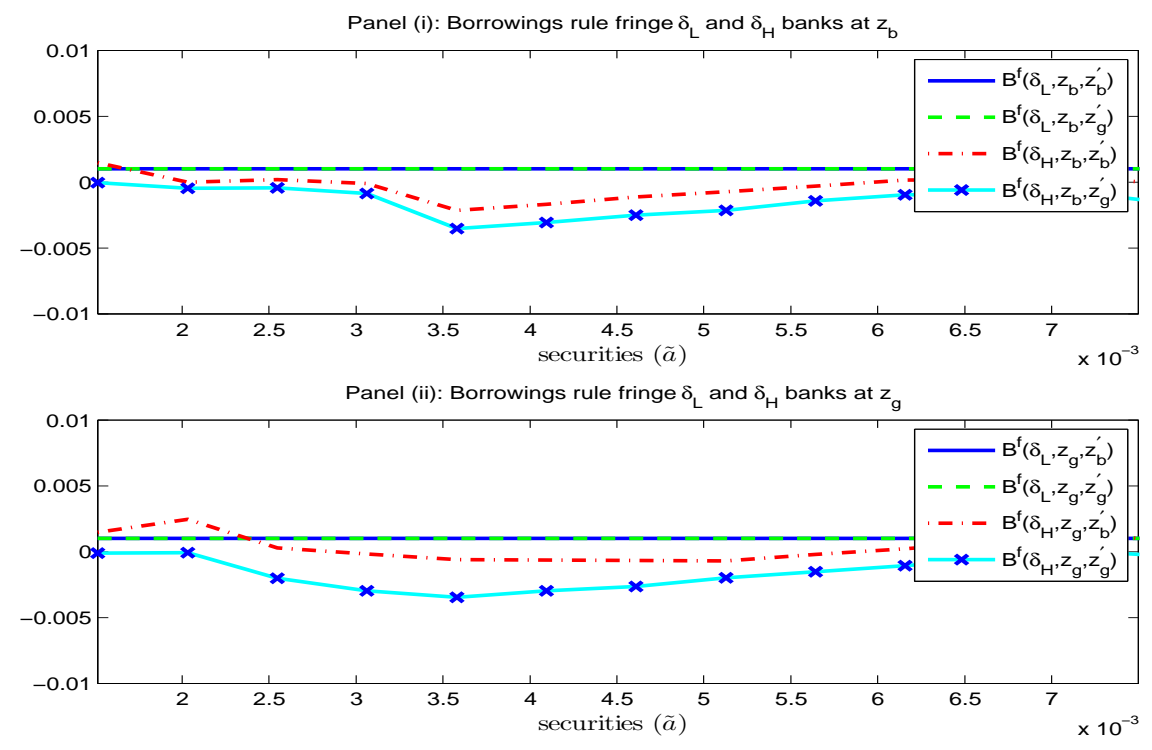

The big and median fringe bank dividend decision rules are illustrated in Figure 9. While dividends are constrained to be non-negative in (9), strictly positive payouts arise only if the bank has sufficiently high assets. The figure shows that a median fringe bank with sufficient assets follows a much more variable dividend policy than the big bank starting in a recession. Panel (ii) shows the dividend policy is procyclical when starting in a boom, but panel (i) exhibits countercyclical behavior when starting from a recession. Much of dividend policy can be understood in terms of differences in short term saving/borrowing between big and small banks. 
Figure 9: Big Bank and Median Fringe Bank Dividend Rule $\mathcal{D}^{\theta}$
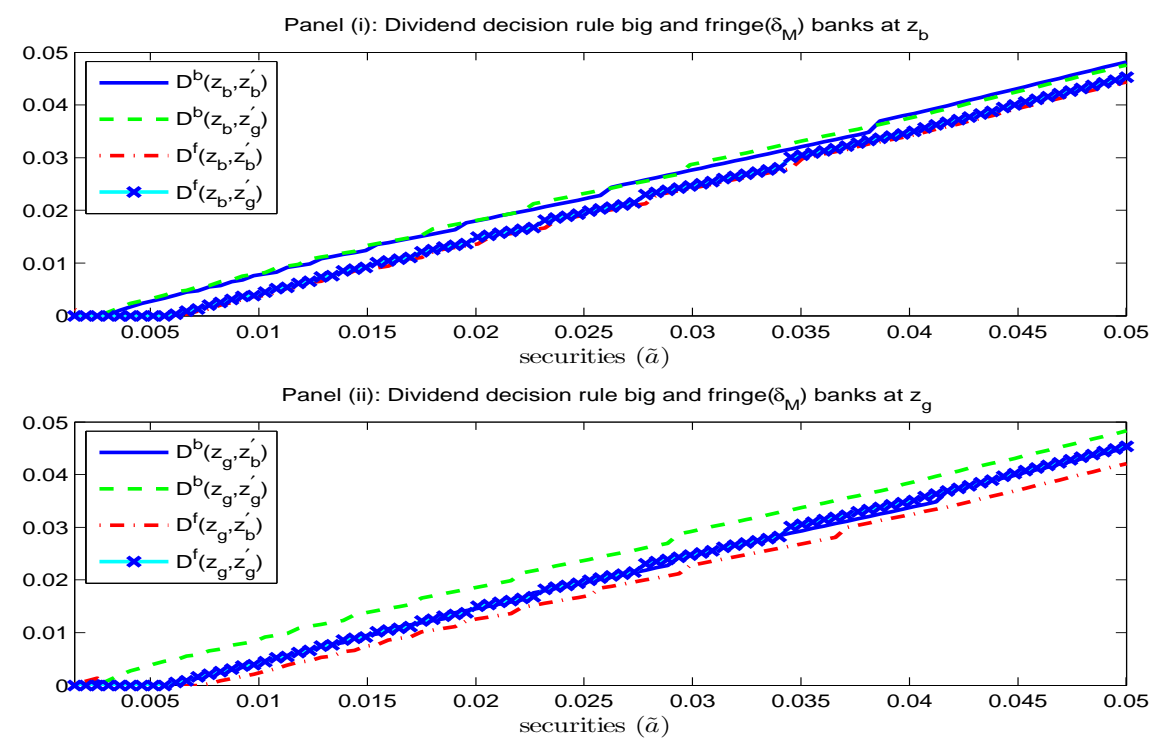

Figure (10) suggests that the biggest fringe banks are more likely to make dividend payouts than the smallest fringe banks.

Figure 10: Fringe Banks Dividend Rule $\mathcal{D}^{\theta}$ (for different values $\delta$ )
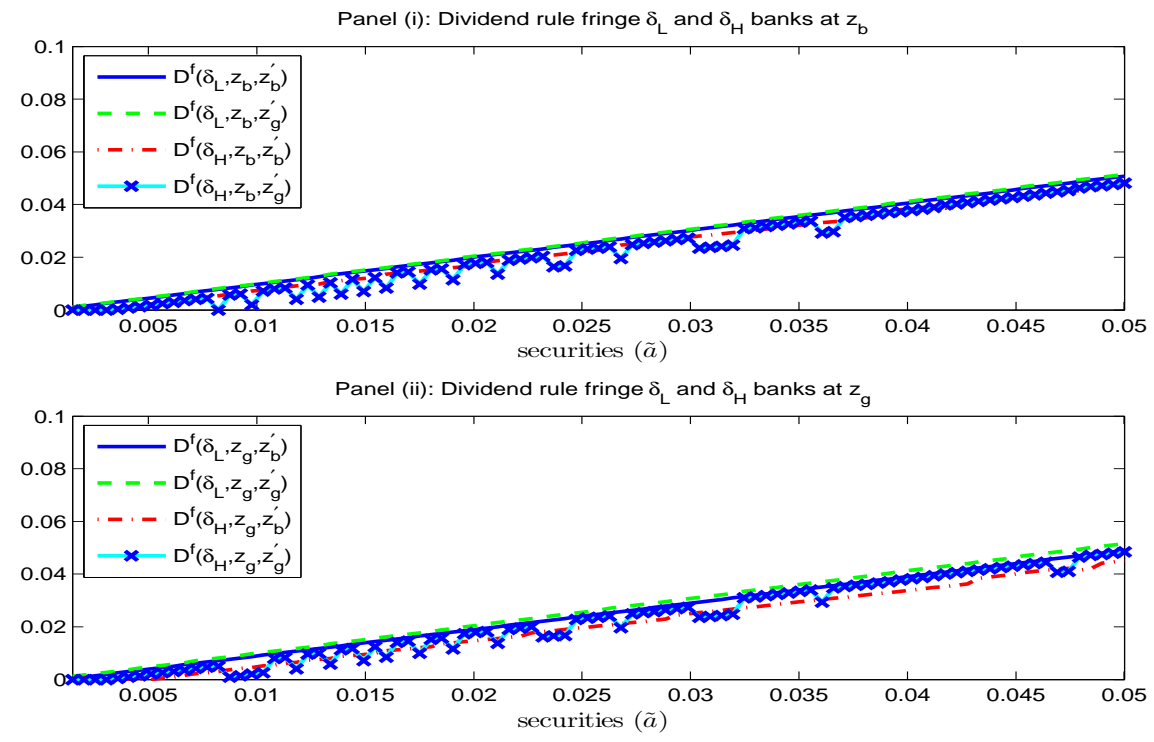

The beginning-of-period equity ratio $\frac{e^{\theta}}{\ell^{\theta}}$ is illustrated in Figure 11. Recall from (4) that 
at the beginning of the period, equity is given by $e^{\theta}=a^{\theta^{\prime}}+\ell^{\theta}-d^{\theta}$ and that capital requirements with $w=0$ are given by $e^{\theta} \geq \varphi^{\theta} \ell^{\theta}$ in (5). The figure also plots the capital requirement $\varphi^{\theta}=0.04$. As evident, the capital requirement is nonbinding for the median fringe bank across all asset levels. The capital requirement for big banks is binding for low levels of assets (and hence independent of the business cycle) but at higher asset levels ratios become higher in recessions relative to booms. The figure also shows that at low asset levels, the fringe bank has a significantly higher ratio than the big bank. At very high asset levels (which are off-the-equilibrium path and not pictured) the relative positions change.

Figure 11: Big Bank and Median Fringe Bank Equity Ratios $e / \ell=\left(a^{\prime}+\ell-d\right) / \ell$

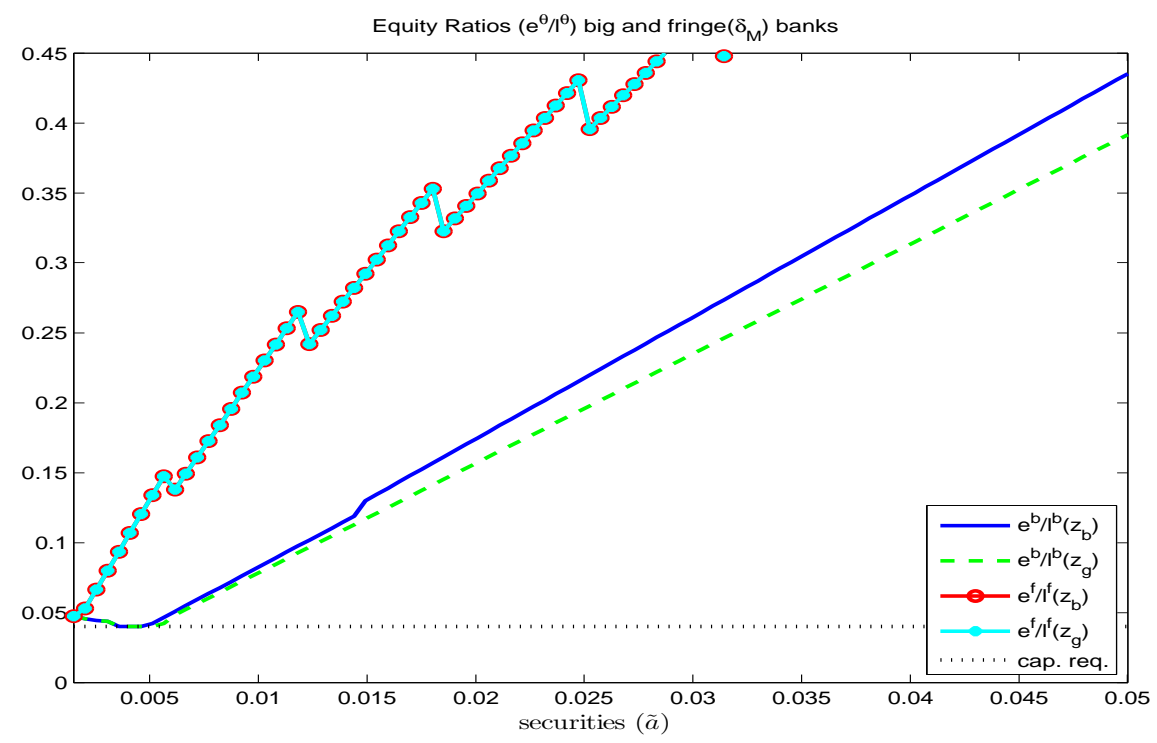

Figure (12) shows that small fringe banks have much higher equity ratios than large fringe banks across all asset levels. In particular, the figure provides evidence of the same type of ranking of capital ratios across big and small fringe banks as evidenced between the median fringe and dominant bank. 
Figure 12: Fringe Banks Equity Ratios $e / \ell=\left(a^{\prime}+\ell-d\right) / \ell($ for different values $\delta)$

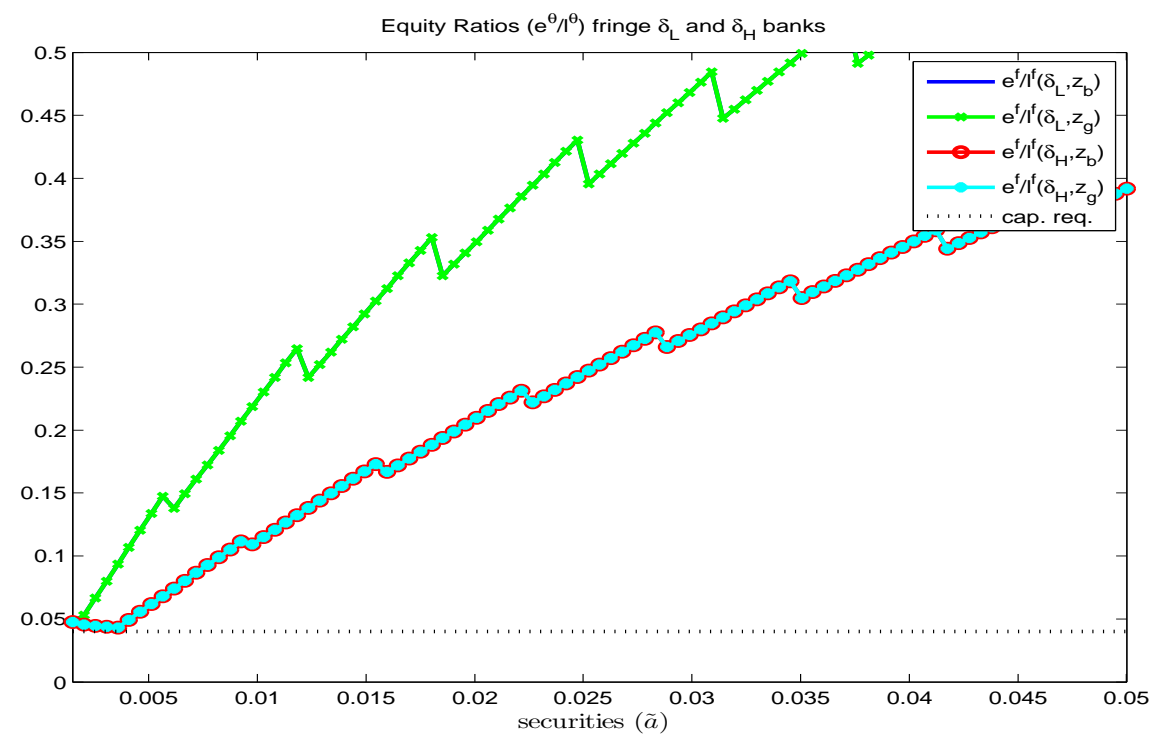

The beginning-of-period loan decision rules for dominant and median fringe banks are illustrated in the top panel of Figure 13. If the dominant bank has sufficient assets, the figure shows that it extends more loans in good than bad times. However at low asset levels, it extends less loans in good than bad times because there is a greater chance of loan losses associated with a downturn. The same is true for its deposit decision. The figure also shows the effects of the capacity constraint on fringe banks. In particular, since the matching function is independent of aggregate state and asset holdings, so are deposit holdings in Panel (ii). Panel (i) shows that fringe banks which have more assets can make more loans (linearly). Since there is a simple ranking of loans and deposits among fringe banks, we do not graph that case. 
Figure 13: Big Bank and Median Fringe Bank Loan and Deposit Decision Rules $\ell^{\theta}$ and $d^{\theta}$
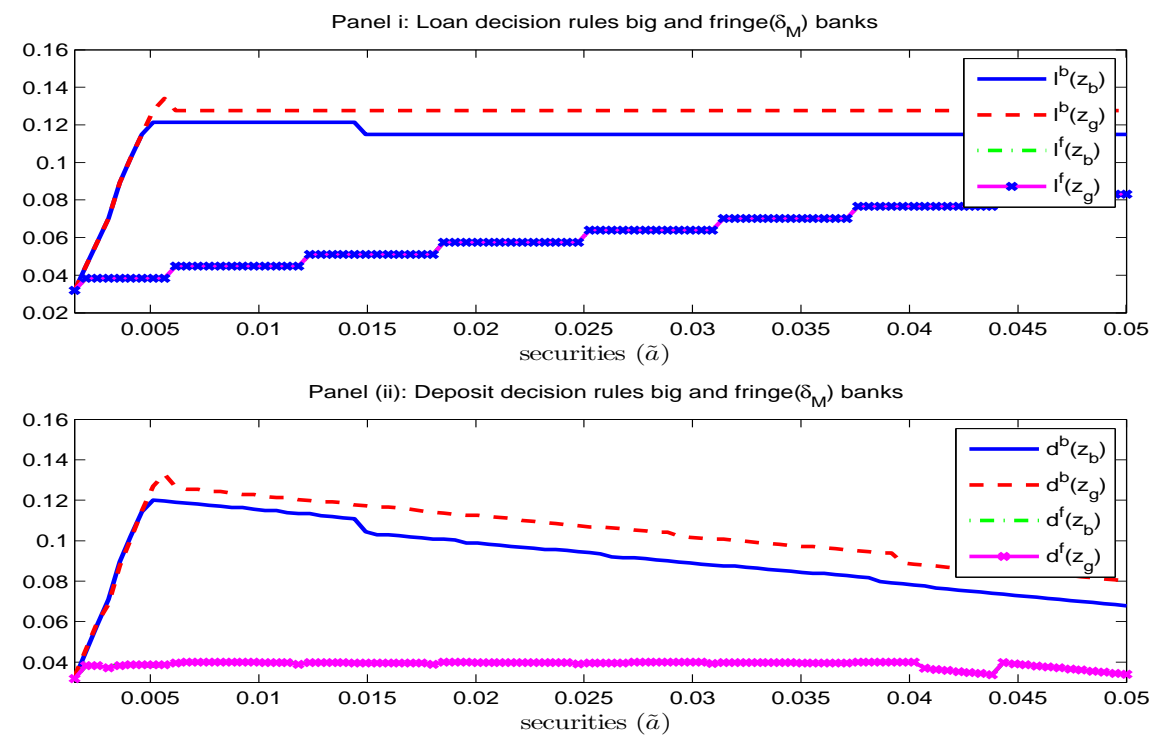

Figure (14) graphs the value function for a potential entrant over the fraction of incumbents $M$. What is important is that it is decreasing in the mass of incumbents; that is, the benefit of entering is smaller the larger the mass of incumbents. Further, there is higher value in good times than bad times.

Figure 14: Value Fringe Bank Potential Entrant

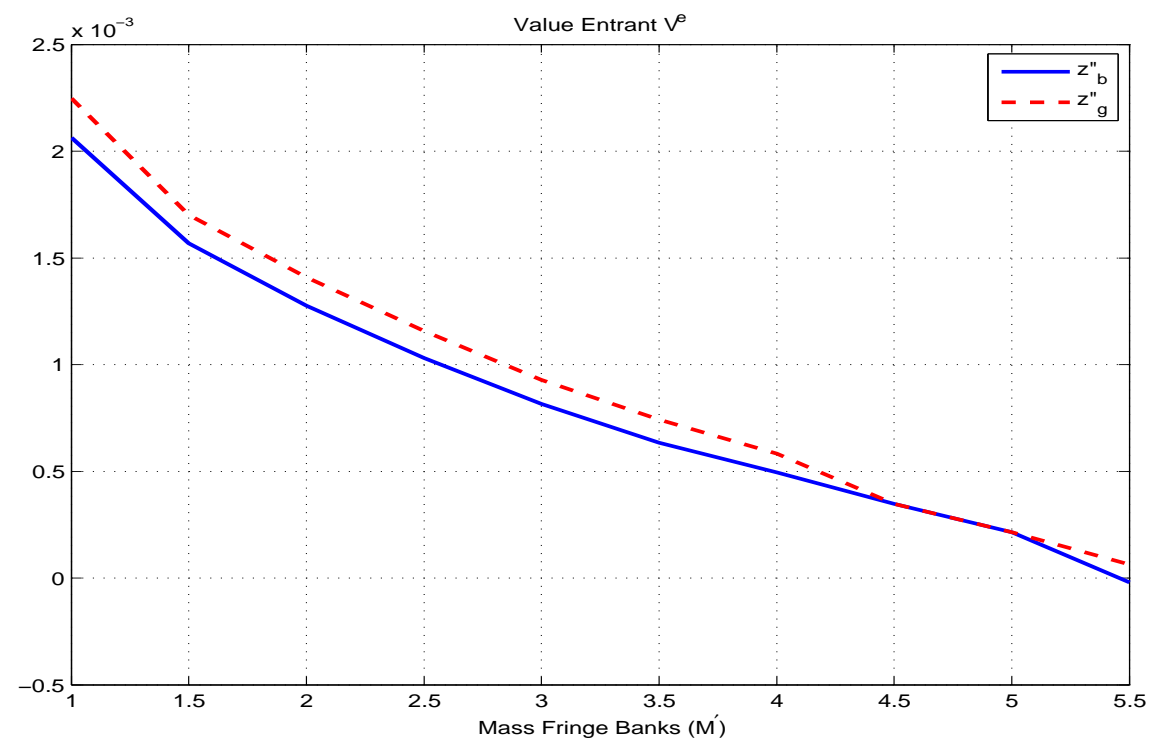


Figure 15 graphs the long run average distribution of bank assets for three different types of fringe banks as well as the dominant bank. Recall that there is no invariant distribution since there is aggregate uncertainty. In this figure, we show the average distribution that arises along the equilibrium path. More specifically, each period the model generates a distribution of fringe banks $\zeta_{t}^{f}(a, \delta)$. This figure presents the average of fifty simulated panels of $\bar{\zeta}^{f}(a, \delta)=\sum_{t=1}^{T} \zeta_{t}^{f}(a, \delta) / T$, where $T=2000$ is the number of simulated periods. ${ }^{21}$ The values presented for the big bank correspond to the fraction of time that the big bank spends along the equilibrium path in each asset level (i.e. the histogram of securities). It is evident from the figure that the distribution of security holdings of the big bank is lower than that of the fringe banks.

Figure 15: Avg. Distribution of Fringe and Big Banks

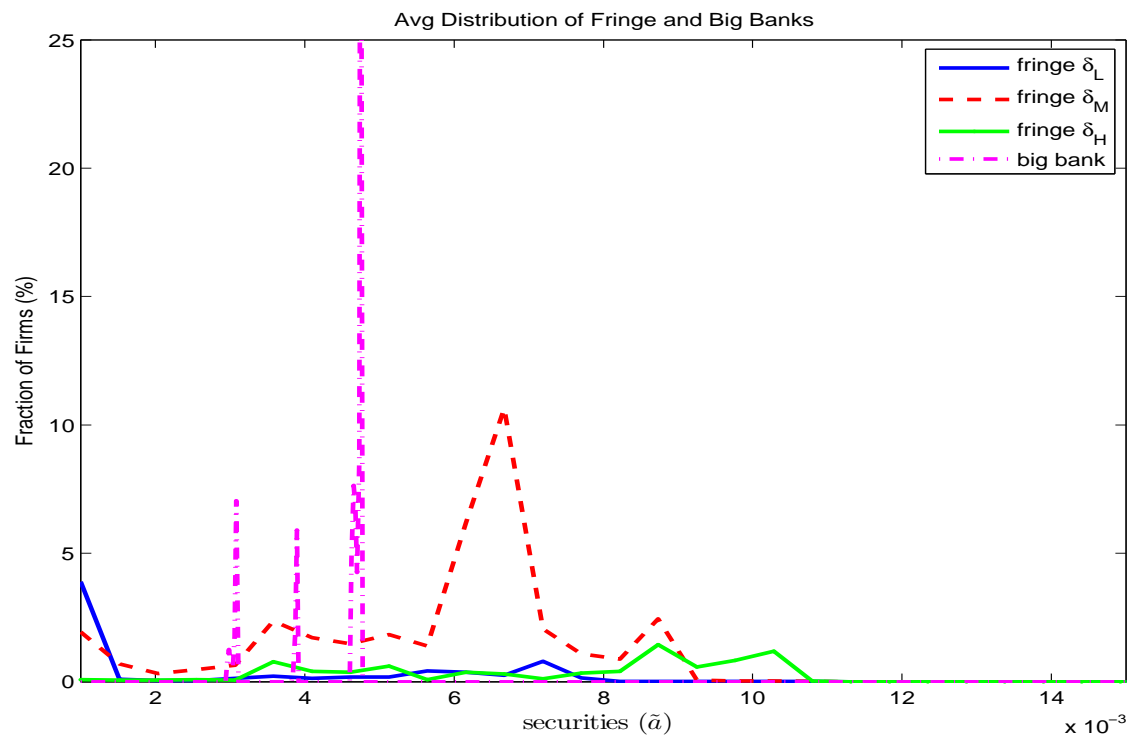

\subsection{Business Cycle Correlations}

We now move on to moments that the model was not calibrated to match, so that these results can be considered a simple test of the model. Table 6 provides the correlation between key aggregate variables with output. ${ }^{22}$ We observe that, as in the data, the model generates countercyclical loan interest rates, exit rates, default frequencies, loan returns, charge-off

\footnotetext{
${ }^{21}$ We discard the first 500 periods of the simulation to avoid dependence on initial conditions.

${ }^{22}$ We use the following dating convention in calculating correlations. Since some variables depend on $z$ and $\zeta$ (e.g. loan interest rates $\left.r^{L}(z, \zeta)\right)$ and some other variables depend on $z, \zeta$, and $z^{\prime}$, (e.g. default frequency $\left.1-p\left(R\left(r^{L}(z, \zeta)\right), z^{\prime}\right)\right)$, Table 6 displays $\operatorname{corr}\left(G D P\left(z, \zeta, z^{\prime}\right), x(z, \zeta)\right)$ and $\operatorname{corr}\left(G D P\left(z, \zeta, z^{\prime}\right), y\left(z, \zeta, z^{\prime}\right)\right)$ where $x(z, \zeta)$ is any variable $x$ that depends on $(z, \zeta)$ and $y\left(z, \zeta, z^{\prime}\right)$ is any variable $y$ that depends on $\left(z, \zeta, z^{\prime}\right)$.
} 
rates, price-cost margins, markups and capital ratios across bank sizes. Moreover, the model generates procyclical entry rates as well as aggregate loans and deposits.

Table 6: Model and Data Business Cycle Correlations

\begin{tabular}{l|cc}
\hline \hline Variable Correlated with Output & Model & Data \\
\hline Loan Interest Rate $r^{L}$ & -0.96 & -0.18 \\
Exit Rate & -0.07 & -0.25 \\
Entry Rate & 0.01 & 0.62 \\
Loan Supply & 0.97 & 0.58 \\
Deposits & 0.95 & 0.11 \\
Default Frequency & -0.21 & -0.08 \\
Loan Interest Return & -0.47 & -0.49 \\
Charge Off Rate & -0.22 & -0.18 \\
Price Cost Margin Rate & -0.47 & -0.47 \\
Markup & -0.96 & -0.19 \\
Capital Ratio Top 1\% (risk-weighted) & -0.16 & -0.75 \\
Capital Ratio Bottom 99\% (risk-weighted) & -0.03 & -0.12 \\
\hline \hline
\end{tabular}

Figure 16 plots a simulation of capital ratios for big and fringe banks across a 100 period sample realization of business cycle shocks.

Figure 16: Capital Ratios over the Business Cycle

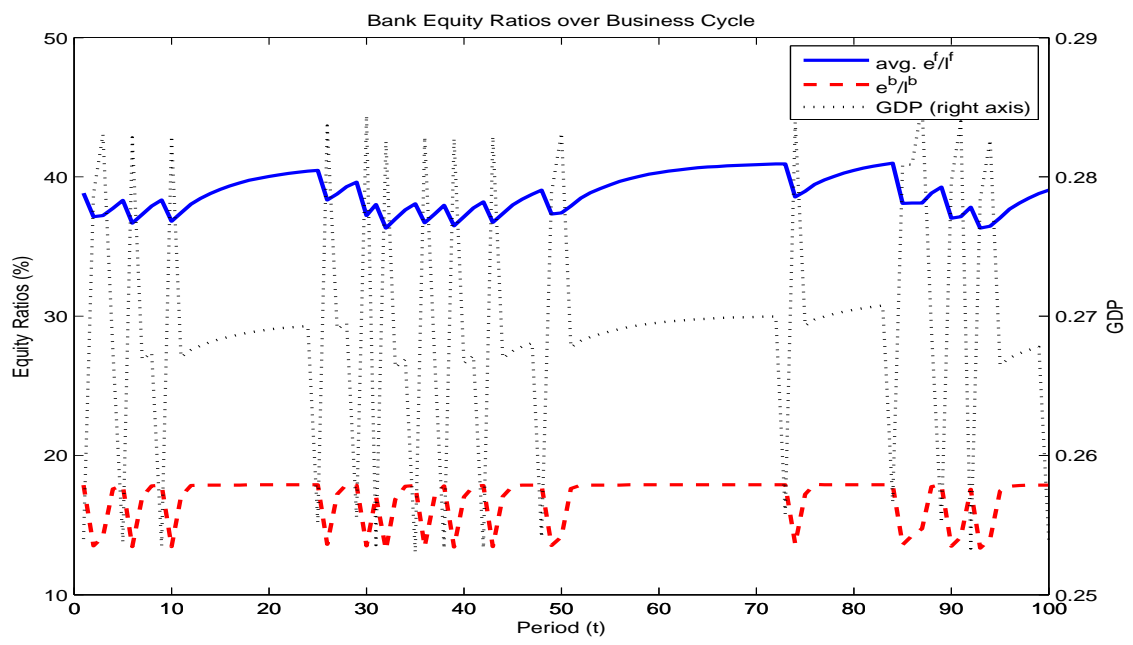

It is clear from this figure that equity ratios are countercyclical. The countercyclicality is mainly driven by changes in equity ratios in periods where $z \neq z^{\prime}$. Intuitively, expansions 
(i.e. periods where $z=z_{b}$ and $z^{\prime}=z_{g}$ ) are preceded by periods where banks reduced their level of securities in order to cover negative profits. The end of the recession is accompanied by an increase in the number of loans at a low level of securities generating a drop in the bank capital ratio. Similarly, before heading into a recession banks accumulate securities in order to cover possible losses. Thus, the beginning of a recession is associated with high capital ratios.

Consistent with the data, the model correlation between fringe banks capital ratio and output is lower than that of the big bank. During tranquil times (i.e. periods where $z=z^{\prime}=$ $z_{g}$ ) the capital ratio of fringe banks increases (tracking output) while big bank's capital ratio remains constant. The reason behind this result is simple. Fringe banks face liquidity risk that big banks do not. In order to extend more loans and avoid being constrained by sudden changes in $\delta$, they accumulate securities whenever possible (evident in the higher long-run average securities observed Figure 15). Figure 5 showed that for states where $z^{\prime}=z_{g}$ the securities accumulation decision rule for the median fringe bank crosses the 45 degree line at a higher level of securities than that of the big bank.

Figure 17: Fraction at Capital Requirement Constraint

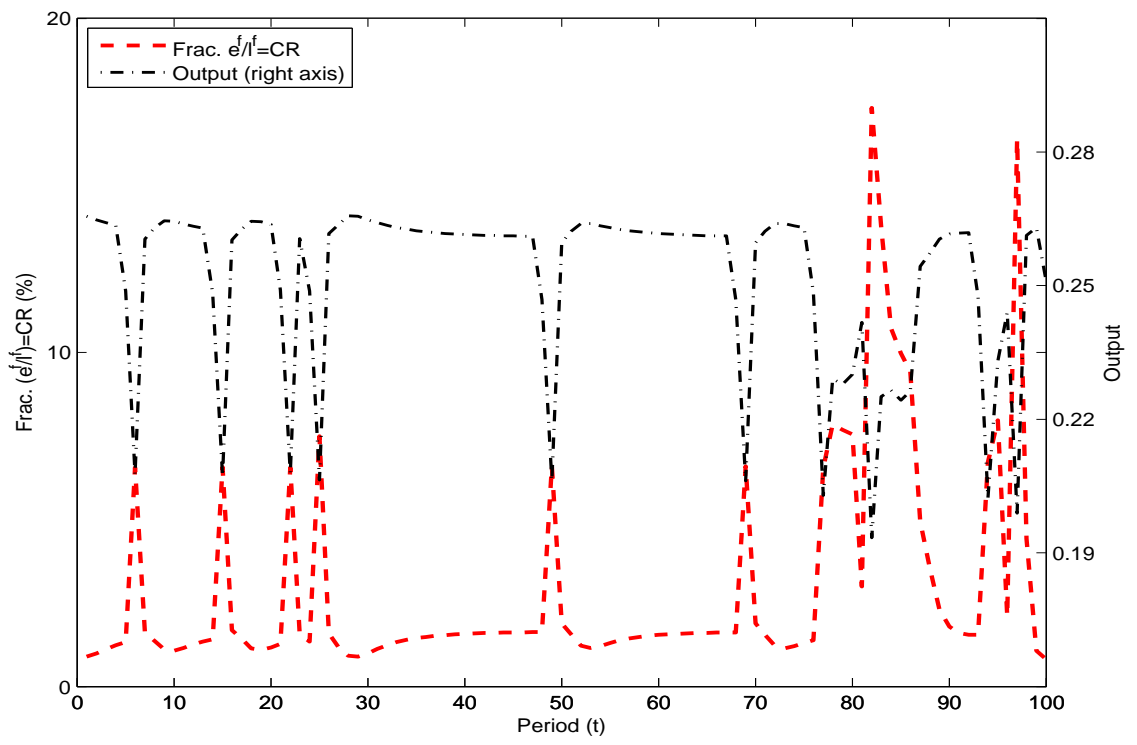

To understand how capital requirements affect how the distribution of banks evolve over time, Figure 17 presents the fraction of banks with a binding capital requirement constraint in any given period along the equilibrium path. It is evident from Figure 17 that the fraction of capital requirement constrained banks rise during downturns (the correlation between the fraction of banks at the capital requirement constraint and output is -0.85). The intuition is simple, banks accumulate securities when times are good that are used to cover losses during bad times. During tranquil times there is also an effect on the fraction of constrained banks 
that is coming from entrants. These banks start with a low level of assets and this generates the small increase in the fraction of constrained banks accompanied by an increase in the total mass of incumbents.

Figure 18 presents the evolution of the mass of fringe banks as well as entry and exit rates over the business cycle. When the economy enters into a recession, a fraction of fringe banks exit. If, as in periods 35 to 40, fringe bank's equity ratios are not high enough, the fraction of banks exiting is larger. The reduction in the number of banks is compensated by entry of new banks. However, in some instances entry is gradual and the level of competition is not restored immediately.

Figure 18: Competition over the Business Cycle
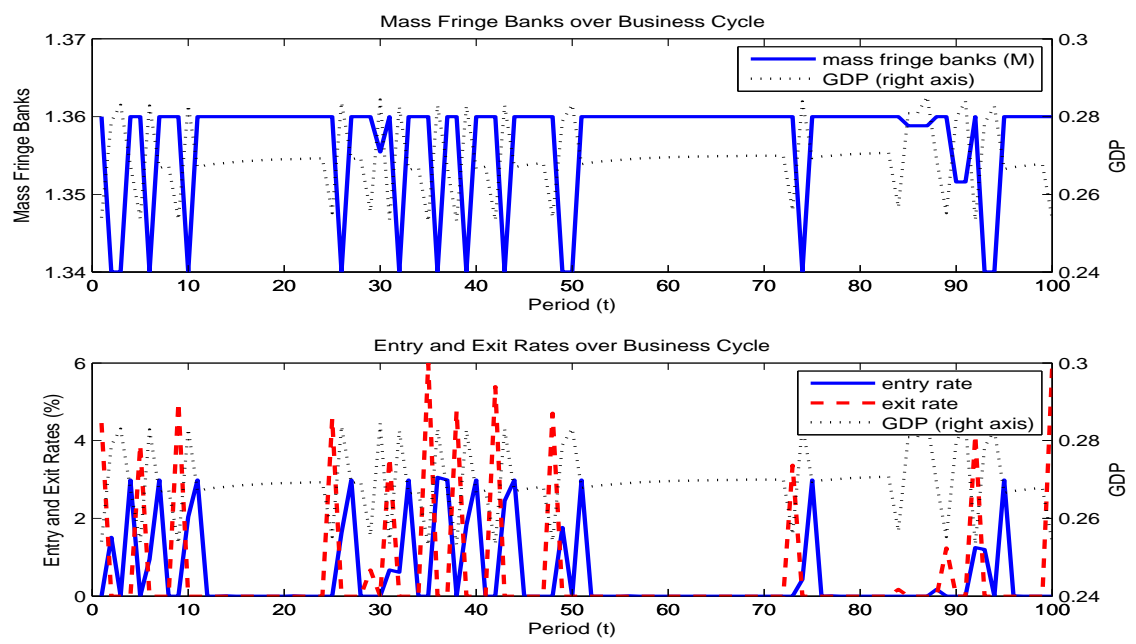

\section{Counterfactuals}

\subsection{Higher capital requirements with imperfect competition}

Here we ask the question "How much does a $50 \%$ increase (from $4 \%$ to 6\%) in capital requirements affect bank exit and outcomes?" Table 7 presents the results of this counterfactual. 
Table 7: Capital Regulation Counterfactual

\begin{tabular}{lcc|c}
\hline \hline & $\begin{array}{c}\text { Benchmark } \\
(\varphi=0.04)\end{array}$ & $\begin{array}{c}\text { Higher Cap. Req. } \\
(\varphi=0.06)\end{array}$ & $\Delta(\%)$ \\
\hline Capital Ratio Top 1\% & 4.23 & 6.09 & 44.19 \\
Capital Ratio Bottom 99\% & 13.10 & 15.67 & 19.57 \\
Exit/Entry Rate (\%) & 1.547 & 0.843 & -45.54 \\
Avg. Loan supply Top 1\% & 10.56 & 10.01 & -5.19 \\
Avg. Loan supply Bottom 99\% & 0.04 & 0.05 & 3.45 \\
Measure Banks 99\% & 2.83 & 2.41 & -14.64 \\
Loan mkt sh. 99\% (\%) & 53.93 & 52.15 & -3.30 \\
Avg. Sec. holdings Top 1\% & 0.46 & 0.61 & 33.17 \\
Avg. Sec. holdings Bottom 99\% & 0.006 & 0.007 & 17.90 \\
Securities to Asset Ratio Top 1\% & 3.68 & 5.57 & 51.19 \\
Securities to Asset Ratio Bottom 99\% & 6.52 & 7.00 & 7.36 \\
Loan Supply & 0.229 & 0.209 & -8.71 \\
$L^{s}$ to Int. Output ratio (\%) & 89.47 & 89.54 & 0.08 \\
Loan Interest Rate (\%) & 6.79 & 7.30 & 7.56 \\
Borrower Project (\%) & 12.724 & 12.742 & 0.14 \\
Default Frequency (\%) & 2.69 & 3.01 & 12.19 \\
Avg. Markup & 111.19 & 123.51 & 11.08 \\
Int. Output & 0.26 & 0.23 & -8.78 \\
Taxes/Output (\%) & 0.07 & 0.03 & -58.97 \\
\hline \hline
\end{tabular}

The capital requirement constraint is more often binding (or close to binding) for large fringe banks and dominant banks. The increase in the capital requirement constraint induces these banks to substitute into securities from loans. We observe this by the larger change in capital ratio for dominant banks than for the average fringe bank $(+44.19 \%$ vs $+19.57 \%)$. Substituting securities for loans reduces the profitability of these banks since loans dominate securities in expected return. Figure 19 presents a comparison of the equity ratios for big banks and large fringe banks (i.e. those with $\delta_{H}$ ) in the benchmark economy (bench.) and in the model with higher capital requirements (c.r.). 
Figure 19: Higher Capital Requirements and Equity Ratios for Big and Fringe Banks
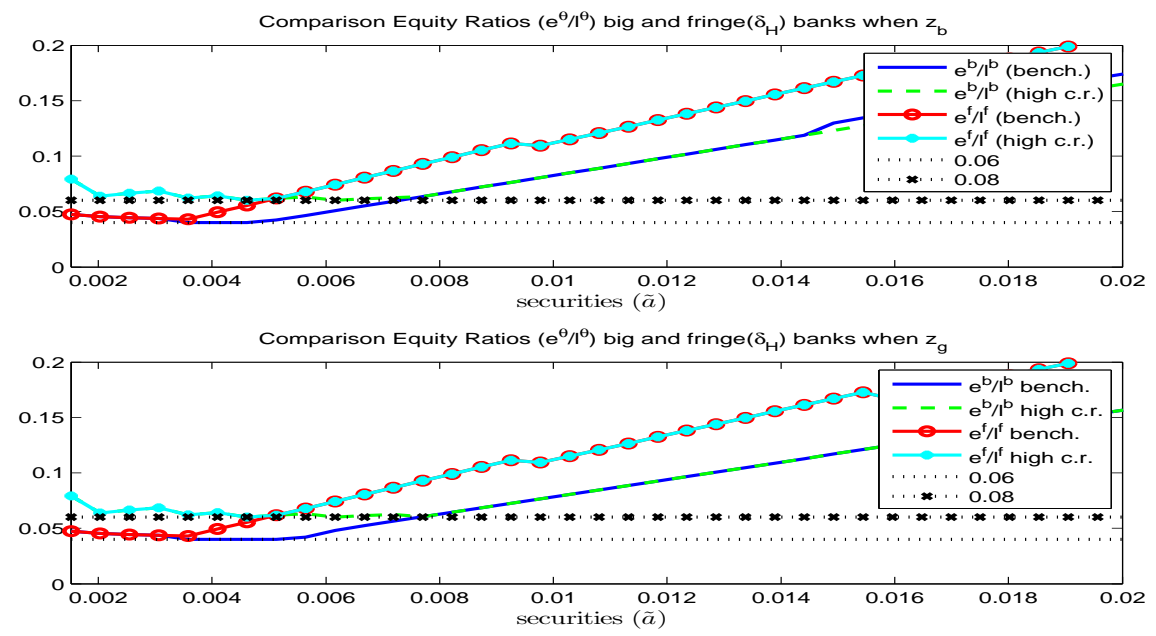

In the benchmark economy, fringe banks with $\delta_{H}$ are close to the capital requirement constraint at low securities levels $\left(\tilde{a}^{f} \leq 0.003\right)$. Figure 19 shows that, at this level of securities, the higher capital requirement induces these fringe banks to increase their equity ratio. This figure also shows that equity ratios for big banks increase in the economy with higher capital requirements. The higher capital ratios presented in Table 7 are the result of not only these changes in decision rules but also the combination of a precautionary motive and an "income" effect. With a higher capital requirement, banks accumulate more assets to avoid an increase in the probability of facing a binding constraint. Moreover, the change in loan market concentration results in higher interest rates and markups, making it easier for incumbent banks to accumulate securities out of retained earnings. As a result, the distribution of assets shifts to the right and since capital ratios are increasing in securities, incumbent banks end up with higher capital ratios on the equilibrium path.

As Table 7 makes clear, increasing capital requirements has the intended effect of reducing exit rates by $45.54 \%$ for small banks. One novelty of our model is that the level of competition is endogenous. The reduction in loan supply by big banks induces entry by small banks. However, the increase in capital requirements (everything else equal) reduces the continuation value of the bank (since their profits are lower). This effect dominates resulting in a smaller measure of fringe banks $(-14.64 \%)$ and a more concentrated industry. The net effect is an increase in concentration, a lower loan supply (-8.71\%), and an associated increase in interest rates $(+7.56 \%)$ and default frequencies $(+12.19 \%)$. The reduction in the exit rate results in a reduction of taxes (over intermediated output) to cover deposit insurance ( $-59 \%$ change). 


\subsection{Interaction between capital requirements and competition}

In this subsection, we ask "How much does a 50\% increase in capital requirements affect bank exit and outcomes under an assumption that all banks are perfectly competitive?" This experiment is meant to assess the interaction between market structure and changes in government policy. It provides a comparison between our work and models with perfect competition and an indeterminate bank size distribution (such as Van Den Heuvel [30] and Aliaga-Diaz and Olivero [1]). Table 8 compares the responses to capital requirement changes in both the benchmark imperfect competition environment to the same policy change in the perfectly competitive model.

Table 8: Higher Capital Requirements and Competition

\begin{tabular}{l|cc|c||cc|c}
\hline \hline & \multicolumn{3}{|c||}{ Benchmark Model } & \multicolumn{3}{c}{ Perfect Competition } \\
Moment & $\varphi=4 \%$ & $\varphi=6 \%$ & Change (\%) & $\varphi=4 \%$ & $\varphi=6 \%$ & Change $(\%)$ \\
\hline Capital Ratio (\%) & 13.10 & 15.667 & 19.57 & 9.92 & 11.77 & 18.64 \\
Exit/Entry Rate (\%) & 1.55 & 0.84 & -45.54 & 0.81 & 0.69 & -14.81 \\
Measure Banks & 2.83 & 2.414 & -14.64 & 5.36 & 5.13 & -4.13 \\
Loan Supply & 0.23 & 0.21 & -8.71 & 0.25 & 0.24 & -2.46 \\
Loan Interest Rate (\%) & 6.79 & 7.30 & 7.56 & 6.27 & 6.43 & 2.50 \\
Borrower Project (\%) & 12.724 & 12.742 & 0.14 & 12.71 & 12.71 & 0.04 \\
Default Frequency (\%) & 2.69 & 3.01 & 12.19 & 2.44 & 2.51 & 3.07 \\
Avg. Markup & 111.19 & 123.51 & 11.08 & 113.91 & 118.58 & 4.11 \\
Output & 0.26 & 0.23 & -8.78 & 0.28 & 0.27 & -2.47 \\
$L^{s}$ to Output ratio (\%) & 89.47 & 89.54 & 0.08 & 89.42 & 89.43 & 0.02 \\
Taxes/Output (\%) & 0.07 & 0.03 & -58.97 & 12.60 & 10.68 & -15.20 \\
\hline \hline
\end{tabular}

To understand the interaction between competition and capital requirements, we start with the competitive analogue to our benchmark. Since our model nests a perfectly competitive environment (our fringe banks), we simply increase the entry cost for the big bank to a value that prevents entry. All other parameters remain identical to those used for the benchmark model. The spirit of this exercise is to endogenously generate an environment where all banks are perfectly competitive (i.e. all banks take prices as given).

Comparing Column 1 and Column 4 of Table 8 makes evident that without competition from big banks, there is a large inflow of fringe banks (2.83 vs 5.36 for an $89.40 \%$ difference). This results in a higher loan supply (8.73\% difference) and lower loan interest rates (-7.55\% difference). Further, this results in slightly less risk taking by borrowers $(-0.12 \%$ difference) and a lower default frequency $(-9.34 \%$ difference). The increase in the number of banks and the reduction in interest rates results in an increase in output $(+8.79 \%$ change).

Table 8 also shows that there is an important reduction in capital ratios $(-24.30 \%$ difference) between the benchmark and the competitive environment from column 1 to column 
4. Recall that the bank capital ratio is given by $e / \ell=1+\left(a^{\prime}-d\right) \ell$. Banks' portfolio composition is driven by the valuable smoothing role that securities provide in cases of bank distress (negative profits) and the cost arising from differences in the expected loan spread of loans over securities. In the competitive environment, lower interest rates make it harder for banks to accumulate equity through retained earnings.

Table 9 compares volatility in the imperfect competition environment and the perfectly competitive environment. It makes clear that the volatility of virtually all aggregates is lower in the perfectly competitive environment. Thus, since the incentives to self-insure are reduced, the shadow value of an extra unit of securities also decreases, generating the lower capital ratios and the difference in portfolio composition between the perfectly competitive economy than in the benchmark.

Table 9: Volatility in Benchmark vs Perfect Competition

\begin{tabular}{lcc|c}
\hline \hline Coefficient of Variation (\%) & $\begin{array}{c}\text { Benchmark } \\
\text { Model }\end{array}$ & $\begin{array}{c}\text { Perfect Competition } \\
\left(\uparrow \Upsilon^{b}\right)\end{array}$ & Change (\%) \\
\hline Loan Interest Rate & 4.92 & 1.78 & -63.78 \\
Borrower Return & 6.99 & 6.17 & -11.75 \\
Default Frequency & 2.08 & 2.15 & 3.36 \\
Int. Output & 7.46 & 2.09 & -72.03 \\
Loan Supply & 7.208 & 1.127 & -84.37 \\
Capital Ratio Fringe & 13.83 & 12.07 & -12.70 \\
Measure Banks & 0.79 & 1.90 & 139.71 \\
Markup & 4.727 & 1.559 & -67.02 \\
Loan Supply Fringe & 3.13 & 1.127 & -64.05 \\
\hline \hline
\end{tabular}

Comparing Columns 4 and 5 of Table 8 shows that even though the rise in capital requirements are not binding on average, banks endogenously increase their capital ratios. Intuitively, since profitability of banks is lower when capital requirements are higher, there is less entry and the measure of fringe banks falls (-4\% change). A lower mass of banks implies a higher loan interest rate $(+2.50 \%$ change $)$ and a default frequency that is larger $(+3.07 \%$ change) than that of the model with lower capital requirements. The higher loan interest rate also results in less projects being operated and a lower intermediated output $(-2.47 \%$ change).

A $50 \%$ increase in capital requirements in the competitive environment results in an increase of $18.64 \%$ in the average capital ratio, larger than that for fringe banks in the benchmark economy. Since the perfectly competitive case is less volatile (as was shown in Table 9), a larger fraction of fringe banks are closer to the minimum level of required capital and this results in the observed differential change in capital ratios for fringe banks across models. The increase in capital ratios and markups results in a considerable reduction in 
the bank exit rate $(-14.81 \%)$ also reflected in the reduction in Taxes/output needed to cover deposit insurance (-15\% change).

Table 10: Business Cycle Correlations in Benchmark vs Perfect Competition

\begin{tabular}{l|c|c|c}
\hline \hline & Benchmark & Perfect Comp. & data \\
\hline Loan Interest Rate $r^{L}$ & -0.96 & -0.36 & -0.18 \\
Exit Rate & -0.07 & -0.16 & -0.25 \\
Entry Rate & 0.01 & -0.19 & 0.62 \\
Loan Supply & 0.97 & 0.61 & 0.58 \\
Deposits & 0.95 & 0.02 & 0.11 \\
Default Frequency & -0.21 & -0.80 & -0.08 \\
Loan Interest Return & -0.47 & 0.65 & -0.49 \\
Charge Off Rate & -0.22 & -0.80 & -0.18 \\
Price Cost Margin Rate & -0.47 & 0.65 & -0.47 \\
Markup & -0.96 & 0.29 & -0.19 \\
Capital Ratio Top 1\% (risk-weighted) & -0.16 & - & -0.75 \\
Capital Ratio Bottom 99\% (risk-weighted) & -0.03 & -0.05 & -0.12 \\
\hline \hline
\end{tabular}

Table 10 presents a comparison of the business cycle correlations between the benchmark model and the perfectly competitive model. It is clear from the table that while some of the predictions of the perfectly competitive model are in line with the data, some important business cycle correlations are not (e.g. the entry rate, loan interest return and markups). ${ }^{23}$ Changes in the level of competition are the main driving force determining the sign of these correlations. In a perfectly competitive environment, changes in the level of competition and concentration that induce movements in interest rates (and consequently markups) are mostly driven by changes in the extensive margin (i.e. changes in the mass of incumbent banks). Table 10 shows that the interest rate and the default frequency in the competitive model are consistent with the data. However, the countercyclicality of the default frequency is 10 times larger than in the data resulting in loan interest returns and markups that are procyclical. On the other hand, the main determinant of the level of competition and concentration in the model with dominant banks are changes in their strategy. The benchmark model with imperfect competition generates loan interest returns and markups which are consistent with countercyclicality we find in the data. The evidence presented in this table (as well as the empirical evidence presented before) provides further support for our benchmark model.

\footnotetext{
${ }^{23}$ Recall that none of the business cycle correlations are part of the set of target moments in the calibration.
} 


\subsection{Risk Taking without capital requirements}

Should there be capital requirements at all? Is the charter value of a bank sufficiently valuable to induce a bank to self-insure and not take on too much risk? In this section, we analyze the model predictions when capital requirements are completely absent. We also study them in the perfectly competitive environment to study the interaction between market structure and regulation.

Table 11: No Capital Regulation Counterfactual

\begin{tabular}{l|cc|c||cc|c}
\hline \hline & \multicolumn{3}{|c||}{ Benchmark Model } & \multicolumn{3}{c}{ Perfect Competition } \\
\hline Moment & $\varphi=4 \%$ & No Cap. Req. & $\Delta(\%)$ & $\varphi=4 \%$ & No Cap. Req. & $\Delta(\%)$ \\
\hline Capital Ratio Top 1\% & 4.23 & 0.19 & -87.41 & - & - & - \\
Capital Ratio Bottom 99\% & 13.10 & 15.73 & 20.05 & 9.92 & 6.67 & -32.71 \\
Exit/Entry Rate (\%) & 1.55 & 4.81 & 210.75 & 0.81 & 1.04 & 28.50 \\
Measure Banks & 2.83 & 4.54 & 60.54 & 5.36 & 5.32 & -0.68 \\
Loan Supply & 0.23 & 0.16 & -28.44 & 0.25 & 0.24 & -3.06 \\
Loan Interest Rate (\%) & 6.79 & 8.47 & 24.83 & 6.27 & 6.47 & 3.11 \\
Borrower Project (\%) & 12.724 & 12.809 & 0.67 & 12.71 & 12.71 & 0.04 \\
Default Frequency (\%) & 2.69 & 4.74 & 76.39 & 2.44 & 2.53 & 3.79 \\
Avg. Markup & 111.19 & 177.73 & 59.84 & 113.91 & 119.74 & 5.12 \\
Int. Output & 0.26 & 0.18 & -28.57 & 0.28 & 0.27 & -3.08 \\
$L^{s}$ to GDP ratio (\%) & 89.47 & 89.63 & 0.18 & 89.42 & 89.44 & 0.02 \\
Taxes/GDP (\%) & 0.07 & 0.11 & 55.80 & 12.60 & 17.22 & 36.72 \\
\hline \hline
\end{tabular}

The benchmark experiment in Table 11 yields an interesting result. When banks are not subject to capital requirements, big banks lower their capital ratios but small banks actually raise them. Bank profitability rises when the constraint is removed, inducing an inflow of fringe banks (the measure of fringe banks rises by 60\%). Both big and fringe incumbent banks reduce the number of loans they make and assets they hold. The big bank does so to strategically raise the interest rate. Fringe banks actually hold higher capital ratios since they want to guard their charter value. This contrasts sharply with the perfectly competitive case where fringe banks lower their capital ratio when the regulation is removed.

\subsection{Countercyclical capital requirements}

Basel III calls for banks to maintain a "countercyclical" capital buffer of up to $2.5 \%$ of risk-based Tier 1 capital. More specifically, a buffer of capital will be required only during periods of credit expansion. Since in our model aggregate credit and aggregate productivity are highly correlated, we implement this change in capital regulation by setting the minimum 
capital requirement to $6 \%$ in periods where $z=z_{b}$ and $8 \%$ in periods where $z_{g}$. Table 12 presents the model predictions.

Table 12: Countercyclical Capital Requirements Counterfactual

\begin{tabular}{lcc|c}
\hline \hline & $\begin{array}{c}\text { Benchmark } \\
(\varphi=0.04)\end{array}$ & $\begin{array}{c}\text { Countercyclical CR } \\
\left.\left(\varphi\left(z_{b}\right)=0.06, \varphi\left(z_{g}\right)=0.07\right\}\right)\end{array}$ & $\Delta(\%)$ \\
\hline Capital Ratio Top 1\% & 4.23 & 25.13 & 494.65 \\
Capital Ratio Bottom 99\% & 13.10 & 12.66 & -3.38 \\
Exit/Entry Rate (\%) & 1.547 & 0.001 & -99.94 \\
Measure Banks 99\% & 2.83 & 1.55 & -45.33 \\
Loan mkt sh. 99\% (\%) & 53.93 & 26.47 & -50.91 \\
Securities to Asset Ratio Top 1\% & 3.68 & 21.09 & 472.48 \\
Securities to Asset Ratio Bottom 99\% & 6.52 & 25.51 & 291.26 \\
Loan Supply & 0.229 & 0.206 & -10.08 \\
$L^{s}$ to Int. Output ratio (\%) & 89.47 & 89.53 & 0.07 \\
Loan Interest Rate (\%) & 6.79 & 7.38 & 8.76 \\
Borrower Project (\%) & 12.724 & 12.748 & 0.19 \\
Default Frequency (\%) & 2.69 & 2.98 & 10.91 \\
Avg. Markup & 111.19 & 0.23 & 2.55 \\
Int. Output & 0.26 & 0.01 & -10.11 \\
Taxes/Output (\%) & 0.07 & -87.57 \\
\hline \hline
\end{tabular}

We observe that there is a large increase in the capital ratio of the big bank who on average moves away from the minimum capital requirement constraint (even the one imposed in good times). The average capital ratio for small banks decrease but this is because of a selection effect. The distribution of small banks results in a larger fraction of high $\delta$ banks than in the benchmark and these are closer to the capital requirement constraint than banks with low $\delta$.

As in our counterfactual with higher capital requirements we note that banks substitute away loans for securities reducing their profitability, generating a lower bank entry and more concentrated industry. The loan market share of the fringe banks is $50.91 \%$ lower.

\subsection{Monetary Policy and Bank Lending}

Kashyap and Stein [24] ask the question "Is the impact of monetary policy on lending behavior stronger for banks with less liquid balance sheets, where liquidity is measured by the ratio of securities to assets? They find strong evidence in favor of this bank lending channel. The result is largely driven by the smaller banks (those in the bottom 95 percent of the size distribution) 
To understand their results, consider two small banks, both of which face limitations in raising uninsured external finance. The banks are alike except that one has a much more liquid balance sheet position than the other. Now imagine that these banks are hit by a contractionary monetary shock, which causes them both to lose insured deposits. In the extreme case where they cannot substitute at all towards other forms of finance, the asset side of their balance sheets must shrink. But the more liquid bank can relatively easily protect its loan portfolio, simply by drawing down on its large buffer stock of securities. In contrast, the less liquid bank is likely to have to cut loans significantly, if it does not want to see its securities holdings sink to a dangerously low level.

Their paper tests two hypotheses. First, $\frac{\partial L_{i t}^{2}}{\partial B_{i t} \partial M_{t}}<0$ where $L_{i t}$ is bank $i$ level of lending, $B_{i t}$ is measure of bank balance sheet strength, and $M_{t}$ is monetary policy indicator (where higher $M$ stands for easier policy). We interpret an expansion in $M$ as a reduction in $r^{a}$. The sign of the cross sectional derivative $\frac{\partial L_{i t}}{\partial B_{i t}}$ is indicative of binding financing constraints which are absent in a Modigliani-Miller world.The second derivative $\frac{\partial\left(\frac{\partial L_{i t}}{\partial B_{i t}}\right)}{\partial M_{t}}$ says that the constraint is loosened when monetary policy is looser. Second, $\frac{\partial L_{i t}^{3}}{\partial B_{i t} \partial M_{t} \partial \text { size }_{i t}}>0$ where size $_{i t}$ refers to bank size class (i.e. for all $i$ in a given size class). The balance sheet effect is expected to be strongest for banks in the smallest size class since the largest banks should have an easier time raising uninsured finance, which would make their lending less dependent on monetary-policy shocks, irrespective of their internal liquidity positions.

To test these hypotheses, Kashyap and Stein run a two-step procedure on the same Call Report Data that we have calibrated our structural model to. In the first step, for each $t$, they run a cross-sectional regression $\Delta L_{i t}=\beta_{t} \cdot B_{i t-1}+$ other separately for each size class (i.e. for all $i$ in a given size class). In the second step, for each size class, they run $\beta_{t}=\sum_{j=0}^{4} \phi_{j} \Delta M_{t-j}+$ other. The hypothesis is $\sum_{j=0}^{4} \phi_{j}<0$ for the smallest size banks.

We implement this policy experiment by analyzing how a permanent reduction in $r^{B}$ to $0 \%$ affects the balance sheet and lending behavior of banks of different sizes. We simulate the model and construct a pseudo-panel of banks under each value of $r^{B}$. We then follow Kashyap and Stein and use a two step procedure to estimate the value of $\frac{\partial\left(\frac{\partial L_{i t}}{\partial B_{i t}}\right)}{\partial M_{t}}$. More specifically, in the the first stage, for both samples and each period, we estimate the following cross-sectional regression:

$$
\Delta L_{i t}=a_{0}+\beta_{t} B_{t-1}+u_{t}
$$

where $\Delta L_{i t}=\frac{\ell_{i t}-\ell_{i t-1}}{\ell_{i t-1}}$ (i.e. the growth rate of loans), and $B_{t}=\frac{a_{t}^{\prime}}{\left(a_{t}^{\prime}+l_{t}\right)}$ (i.e. the fraction of securities to total assets) is the measure of liquidity as defined by Kashyap and Stein. From this set of regressions we obtain a sequence of $\beta_{t}$ under each monetary regime. Then, with the sequence of $\beta_{t}$ as hand, we estimate the second stage as follows

$$
\beta_{t}=b_{0}+b_{1} \Delta \text { output }_{t}+\phi d M_{t}
$$

where $\Delta$ output $_{t}$ is the growth rate of intermediated output and $d M_{t}$ is a dummy variable that equals 1 if the observation belongs to the sample with $r^{B}=0 \%$. A negative coefficient 
is consistent with the findings in Kashyap and Stein since that means that $\beta_{t}$ are on average lower with the easier monetary policy or that $\frac{\partial\left(\frac{\partial L_{i t}}{\partial B_{i t}}\right)}{\partial M_{t}}<0$. Following Kashyap and Stein we focus on the small banks (our fringe sector) based on the idea that these banks are least likely to be able to frictionlessly raise uninsured finance. Table 13 presents the estimated coefficients for two samples of small banks (when sorted by deposits).

Table 13: Monetary Policy and Bank Lending

\begin{tabular}{|c|c|c|}
\hline \multirow[t]{3}{*}{ Sample } & "Bottom 99\% & Bottom 92\% \\
\hline & \multicolumn{2}{|c|}{ Dep. Variable } \\
\hline & $\beta_{t}$ & $\beta_{t}$ \\
\hline Monetary Policy: $d M_{t}$ & -0.929 & -1.177 \\
\hline s.e. & $0.2575^{* * *}$ & $0.2521^{* * *}$ \\
\hline$\Delta$ output $_{t}$ & 2.53 & 2.306 \\
\hline s.e. & $0.619^{* * *}$ & $0.586^{* * *}$ \\
\hline constant & 2.01 & 2.07 \\
\hline s.e. & $0.184^{* * *}$ & $0.179^{* * *}$ \\
\hline $\mathrm{N}$ & 5000 & 5000 \\
\hline$R^{2}$ & 0.35 & 0.46 \\
\hline
\end{tabular}

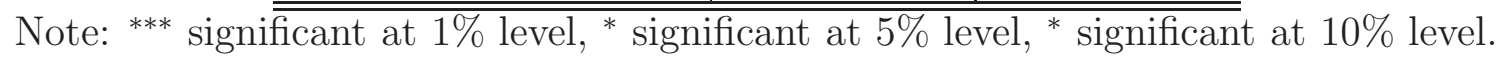

As evident from Table 13 our results are consistent with those presented in Kashyap and Stein. In particular, we find that $\frac{\partial\left(\frac{\partial L_{i t}}{\partial B_{i t}}\right)}{\partial M_{t}}<0$ (i.e. relaxing monetary policy reduces the link between lending and the level of liquidity at the bank level) and we also find that $\frac{\partial L_{i t}^{3}}{\partial B_{i t} \partial M_{t} \partial s i z e_{i t}}>0$ (i.e. the mechanism at play is stronger for the smallest size banks). 
Table 14: Aggregate and Industry Effects of Monetary Policy

\begin{tabular}{lcc|c}
\hline \hline & $\begin{array}{c}\text { Benchmark } \\
(\varphi=0.04)\end{array}$ & $\begin{array}{c}\text { Lower } r^{B} \\
(\varphi=0.04)\end{array}$ & $\Delta(\%)$ \\
\hline Capital Ratio Top 1\% & 4.23 & 5.43 & 28.43 \\
Capital Ratio Bottom 99\% & 13.10 & 13.39 & 2.19 \\
Exit/Entry Rate (\%) & 1.547 & 1.904 & 23.09 \\
Loans to Asset Ratio Top 1\% & 96.31 & 73.84 & -23.33 \\
Loans to Asset Ratio Bottom 99\% & 93.47 & 43.47 & -53.49 \\
Measure Banks 99\% & 2.83 & 11.63 & 311.07 \\
Loan mkt sh. 99\% (\%) & 53.93 & 45.69 & -15.28 \\
Avg. Sec. holdings Top 1\% & 0.458 & 0.961 & 109.80 \\
Avg. Sec. holdings Bottom 99\% & 0.006 & 0.001 & -79.41 \\
Loan Supply & 0.229 & 0.344 & 50.19 \\
$L^{s}$ to Int. Output ratio (\%) & 89.47 & 89.23 & -0.26 \\
Loan Interest Rate (\%) & 6.79 & 3.85 & -43.23 \\
Borrower Project (\%) & 12.724 & 12.652 & -0.57 \\
Default Frequency (\%) & 2.69 & 1.61 & -40.02 \\
Avg. Markup & 111.19 & 35.20 & -68.34 \\
Int. Output & 0.26 & 0.39 & 50.58 \\
Taxes/Output (\%) & 0.07 & 0.09 & 24.99 \\
\hline \hline
\end{tabular}

To compare the "monetary policy" results in this subsection to the previous "regulatory policy" results of the earlier subsections, Table 14 presents the aggregate and industry effects of the policy change. Reducing the cost of bank borrowing increases the value of the bank and results in a large influx of fringe banks (the entry rate goes up $+23.09 \%$ ). This results in a higher loan supply $(+50.19 \%)$ that in turn induces a lower interest rate $(-43.23 \%)$. Lower profitability associated with the mass of new entrants means that incumbents profitability falls and induces those incumbents to increase their capital ratios to help prevent exit. Lower incumbent profitability is evident in the higher exit rate $(+23.09 \%)$. One of the benefits of relaxing monetary policy is that it results in a higher level of intermediated output $(+50.58 \%)$ at the cost of increasing taxes to output $(+24.99 \%)$ to cover for deposit insurance due to the higher fraction of banks exiting in equilibrium.

\section{Directions for Future Research}

As discussed in an important new empirical paper by Jimenez, et. al. [23], credit demand and balance- sheet channels have testable predictions at the firm or bank level, but one aspect of the bank risk-taking channel involves compositional changes in credit supply at the bank-firm level. Unfortunately, our call report data does not allow us to identify this aspect 
of the bank risk-taking channel, so we have not included borrower heterogeneity in this paper. Bank risk-taking in our framework is associated with loan extension across particular states of the world associated with aggregate shocks and bank level heterogeneity. It would, however, be possible to extend our framework to include borrower heterogeneity. Specifically, here borrowers are ex-ante identical but ex-post heterogeneous. Private information about borrower outside options with one-period lived borrowers results in pooling loan contracts and one aggregate state dependent loan rate. In our previous work [12], our spatial framework included regional specific shocks to borrower production technologies which were observable and contractible generating heterogeneity in interest rates across different "type" borrowers. To address the type of heterogeneity found in the Jimenez, et. al. data, we could include heterogeneity in the success/failure across borrower projects. In particular, the success of a borrower's project, which occurs with probability $p_{h}\left(R_{t}, z_{t+1}\right)$, could be independent across borrowers of type $h$ but depends on the borrower's choice of technology $R_{t} \geq 0$ at the beginning of the period and an aggregate technology shock at the end of the period denoted $z_{t+1}$. Riskier borrowers would then be modeled, ceteris paribus, through the assumption that $p_{H}\left(R_{t}, z_{t+1}\right)<p_{L}\left(R_{t}, z_{t+1}\right)<$ where $H$ stands for "High" risk and $L$ stands for "Low" risk. Banks would continue to pool the idiosyncratic uncertainty within a risk class, but depending on informational assumptions associated with screening could offer separating contracts to borrowers resulting in a distribution of loan rates much the same way as in Chatterjee, et. al. [10]. 


\section{References}

[1] Aliaga Diaz, R. and M., Olivero (2011) "Do Bank Capital Requirements Amplify Business Cycles? Bridging the Gap between Theory and Empirics," Macroeconomic Dynamics, doi:10.1017/S1365100510000623, 1-38.

[2] Allen, F., E. Carletti and R. Marquez (2011) "Credit Market Competition and Capital Regulation", Review of Financial Studies, 24, p. 983-1018.

[3] Allen, F. and D. Gale (2004) "Competition and Financial Stability", Journal of Money, Credit, and Banking, 36, p. 453-80.

[4] Arellano, Manuel and Bond, Stephen, (1991) "Some Tests of Specification for Panel Data: Monte Carlo Evidence and an Application to Employment Equations," Review of Economic Studies, 58(2), p. 277-97.

[5] Basel Committee on Banking Supervision (2010) "Basel III: International framework for liquidity risk measurement, standards, and monitoring", Bank for International Settlements.

[6] Berger, A. L. Klapper and R. Turk-Ariss (2008) "Banking competition and financial stability," Journal of Financial Services Research, pp. 99-118.

[7] BIS (2010) "Guidance for national authorities operating the countercyclical capital buffer," Basel Committee on Banking Supervision.

[8] BIS (2011) "Basel III: A global regulatory framework for more resilient banks and banking systems," Basel Committee on Banking Supervision.

[9] Boyd, J. and G. De Nicolo (2005) "The Theory of Bank Risk-Taking and Competition Revisited", Journal of Finance, 60, p. 1329-43.

[10] Chatterjee, S., D. Corbae, M. Nakajima, V.Rios-Rull (2007) "A Quantitative Theory of Unsecured Consumer Credit with Risk of Default", Econometrica, 75, p. 1525-89.

[11] Cociuba, S., M. Shukayev, and A. Ueberfeldt (2011) "Do Low Interest Rates Sow the Seeds of Financial Crises?", mimeo.

[12] Corbae, D. and P. D'Erasmo (2011) “A Quantitative Model of Banking Industry Dynamics", mimeo.

[13] De Nicolo, G., A. Gamba, M. Lucchetta (2011) "Capital Regulation, Liquidity Requirements and Taxation in a Dynamic Model of Banking", mimeo.

[14] Diamond, D. and P. Dybvig (1983) "Bank Runs, Deposit Insurance, and Liquidity", Journal of Political Economy, 91, p. 401-19. 
[15] Diaz-Gimenez, J., E. Prescott, F. Alvarez, and T. Fitzgerald (1992) "Banking in Computable General Equilibrium Models", Journal of Economic Dynamics and Control, 16, p.533-60.

[16] Diebold F. and K. Yilmaz (2009) "Measuring Financial Asset Return and Volatility Spillovers, with Application to Global Equity Markets," Economic Journal, 119(534), 158-171.

[17] Estrella, A. (2004) "The Cyclical Behavior of Optimal Bank Capital," Journal of Banking and Finance, 28, p. 1469-1498.

[18] Ericson, R. and A. Pakes (1995) "Markov-Perfect Industry Dynamics: A Framework for Empirical Work", Review of Economic Studies, 62, p. 53-82.

[19] Farias, V., B. Ifrach and G. Weintraub (2011) "A Framework for Dynamic Oligopoly in Concentrated Industries", manuscript.

[20] Gale, D. and O. zgr (2010) "Are Bank Capital Ratios too High or too Low? Incomplete Markets and Optimal Capital Structure“, Journal of the European Economic Association, 3(2-3), p. 690-700.

[21] Gertler, M. and N. Kiyotaki (2009) "Financial Intermediation and Credit Policy in Business Cycle Analysis", mimeo.

[22] Gowrisankaran, G. and T. Holmes (2004) "Mergers and the Evolution of Industry Concentration: Results from the Dominant-Firm Model," RAND Journal of Economics, $35(3)$, p. 561-582.

[23] Jimenez, G., S. Ongena, J.L. Peydro, and J. Saurina (2011) "Hazardous Times for Monetary Policy: What Do Twenty-Three Million Bank Loans Say About the Effects of Monetary Policy on Credit Risk-Taking? ", forthcoming Econometrica.

[24] Kashyap A. and J. Stein (2000) "What Do a Million Observations on Banks Say about the Transmission of Monetary Policy?" American Economic Review, vol. 90(3), p. 407428.

[25] Krusell P. and Anthony Smith (1998) "Income and Wealth Heterogeneity in the Macroeconomy," Journal of Political Economy, 106(5), 867-896.

[26] Martinez-Miera, D. and R. Repullo (2010) "Does Competition Reduce the Risk of Bank Failure?," Review of Financial Studies, 23, p. 3638-3664.

[27] Pakes, A. and P. McGuire (1994) "Computing Markov Perfect Nash Equilibrium: Numerical Implications of a Dynamic Differentiated Goods Model", RAND Journal of Economics, 25, p. 555-589. 
[28] Repullo, R. and J. Suarez (2012) "The Procyclical Effects of Bank Capital Regulation," CEPR Discussion Papers 8897.

[29] Tauchen, G. (1986) "Finite state markov-chain approximations to univariate and vector autoregressions," Economics Letters, 20(2), p. 177-181.

[30] Van Den Heuvel, S. (2008) "The Welfare Cost of Bank Capital Requirements" Journal of Monetary Economics, 55, p. 298-320.

[31] Zhu, H. (2008) "Capital Regulation and Banks' Financial Decisions," International Journal of Central Banking, 4, p. 165-211.

\section{Computational Appendix}

We solve the model using an extension of the algorithm proposed by Krusell and Smith [25] or Farias et. al. [19] adapted to this environment. This entails approximating the distribution of banks $\zeta=\{\hat{a}, \hat{\delta}, \zeta(\tilde{a}, \delta)\}$ by a finite number of moments. The moments we use are the mean asset $\bar{A}$ and deposit $\bar{\delta}$ level of fringe banks as well as the mass of fringe banks $M$, along with the asset level of the dominant bank. To keep the state space simple, we also assume that $\bar{\delta}$ is the unconditional mean of the $G\left(\delta^{\prime}, \delta\right)$ process (after checking whether it was a good assumption). Unlike the competitive framework in Krusell and Smith, when making loan decisions, the dominant bank needs to take into account how changes in its behavior affects the total loan supply of fringe banks. This reaction function also depends on the industry distribution. While Farias et. al. also have a reaction function, they base theirs only on the average firm's static profit function. For the same reasons as stated above, in the reaction function we approximate the behavior of the fringe segment of the market with the dynamic decision rules (which unlike Farias et. al. includes exit) of the "average" fringe bank, i.e. a fringe bank that holds the mean asset and deposit levels.

More specifically, in the decision problem of the dominant bank, instead of the state vector being given by $V^{b}(\tilde{a}, \delta, z, \zeta)$ and $W^{b}\left(\ell, d, a^{\prime}, \zeta, \delta, z^{\prime}\right)$, recognizing that we are approximating the fringe part of $\zeta$ by $\bar{A}$ and $M$, we use $V^{b}(\tilde{a}, z, \bar{A}, M)$ and $W^{b}\left(\pi, a^{\prime}, z, z^{\prime}, \tilde{a}, \bar{A}, M\right)$, respectively. We do not include $\delta$ since it is never binding for the big bank. Further, it is sufficient to know $\pi$ rather than $(\ell, d)$ economizing on one state variable. Instead of the law of motion for the distribution $\zeta^{\prime}=H\left(z, z^{\prime}, \zeta\right)$ in (30) we approximate the fringe part by $\bar{A}^{\prime}=H^{A}\left(z, z^{\prime}, a^{b}, \bar{A}, M\right)$ and $M^{\prime}=H^{M}\left(z, z^{\prime}, a^{b}, \bar{A}, M\right)$. Finally, we approximate the equation defining the "reaction function" $\ell+L^{f}(\zeta, \ell)=L^{d}\left(r^{L}, z\right)$ in $(25)$ by $\ell+L^{f}\left(z, a^{b}, \bar{A}, M, \ell\right)=L^{d}\left(r^{L}, z\right)$ with

$$
L^{f}\left(z, a^{b}, \bar{A}, M, \ell\right)=\ell^{f}\left(z, a^{b}, \bar{A}, M, \ell\right) \times M .
$$

The mass of fringe banks depends on entry and exit decisions, which is why our "reaction function" must consider dynamic decisions unlike that in Farias, et. al.

A similar set of changes to the state vector need to be made to the problem of fringe banks (except that the deposit capacity constraints almost always bind so we must keep 
that state variable). In particular, $V^{f}(\tilde{a}, \delta, z, \zeta)$ is replaced by $V^{f}\left(\tilde{a}, \delta, z, a^{b}, \bar{A}, M\right)$ and $W^{f}\left(\ell, d, a^{\prime}, \zeta, \delta, z^{\prime}\right)$ is replaced by $W^{f}\left(\pi, a^{\prime}, \delta, z, z^{\prime}, a^{b}, \bar{A}, M\right)$. As before, the law of motion for the distribution $\zeta^{\prime}=H\left(z, z^{\prime}, \zeta\right)$ in (30) is approximated by $\bar{A}^{\prime}=H^{A}\left(z, z^{\prime}, a^{b}, \bar{A}, M\right)$, $M^{\prime}=H^{M}\left(z, z^{\prime}, a^{b}, \bar{A}, M\right)$, and $a^{b^{\prime}}=a^{b^{\prime}}\left(a^{b}, z, \bar{A}, z^{\prime}\right)$. Finally, the reaction function in equation (25) uses the decision rule that solves the big bank loan choice problem; in particular $L^{d}\left(r^{L}, z\right)=\ell^{b}\left(a^{b}, a, \bar{A}, M\right)+L^{f}\left(z, a^{b}, \bar{A}, M, \ell^{b}\left(a^{b}, a, \bar{A}, M\right)\right)$.

In order for the dominant bank to know how the fringe banks will react to its decisions, it must know how fringe banks will behave when it takes off-the-equilibrium path actions. To that end, we must introduce an auxiliary problem for the fringe banks where they choose optimally across any possible action of the big bank $\ell$. The statement of the auxiliary problem is the same as for the fringe bank above except that the equation defining the reaction function in equation $(25)$ is given by $L^{d}\left(r^{L}, z\right)=\ell+L^{f}\left(z, a^{b}, \bar{A}, M, \ell\right)$.

The algorithm is given by:

1. Guess aggregate functions. That is, guess $\left\{h_{i}^{a}\right\}_{i=0}^{5}$ and $\left\{h_{i}^{m}\right\}_{i=0}^{5}$ to get

$$
\begin{aligned}
\log \left(\bar{A}^{\prime}\right) & =h_{0}^{a}+h_{1}^{a} \log (z)+h_{2}^{a} \log \left(a^{b}\right)+h_{3}^{a} \log (\bar{A})+h_{4}^{a} \log (M)+h_{5}^{a} \log \left(z^{\prime}\right) \\
\log \left(M^{\prime}\right) & =h_{0}^{m}+h_{1}^{m} \log (z)+h_{2}^{m} \log \left(a^{b}\right)+h_{3}^{m} \log (\bar{A})+h_{4}^{a} \log (M)+h_{5}^{a} \log \left(z^{\prime}\right)
\end{aligned}
$$

Make an initial guess of $\ell^{f}\left(\bar{A}, z, a^{b}, M, \ell ; \bar{\delta}\right)$ (i.e. the solution to the auxiliary problem) that determines the reaction function

$$
L^{f}\left(z, a^{b}, \bar{A}, \ell\right)=\ell^{f}\left(\bar{A}, z, a^{b}, \ell\right) \times M .
$$

2. Solve the dominant bank problem to obtain the big bank value function and decision rules: $V^{b}, \ell^{b}, a^{b^{\prime}}, d^{b}, B^{b^{\prime}}$ and $x^{b}$.

3. Solve the problem of fringe banks to obtain the fringe bank value function and decision rules: $V^{f}, \ell^{f}, a^{f^{\prime}}, d^{f}, B^{f^{\prime}}$ and $x^{f}$.

4. Using the solution to the fringe bank problem $V^{f}$, solve the auxiliary problem to obtain $\ell^{f}\left(\bar{A}, z, a^{b}, M, \ell ; \bar{\delta}\right)$.

5. Solve the entry problem of the fringe bank and big bank to obtain entry decision rules.

\section{Simulation}

(a) Guess distribution of fringe banks over $\tilde{a}$ and $\delta, \zeta_{0}(a, \delta)$. Compute $\bar{A}_{0}=\sum_{i, j} a_{i} \zeta_{0}\left(a_{i}, \delta_{j}\right)$ and and $M_{0}=\sum_{i, j} \zeta_{0}\left(a_{i}, \delta_{j}\right)$.

(b) Guess initial $a^{b}$.

(c) Simulate a path of $\left\{z_{t}\right\}_{t=0}^{T}$.

(d) Using decision rules for big banks obtain $\ell_{t}^{b}, d_{t}^{b}, a_{t+1}^{b}, B_{t+1}^{b}$ and $\tilde{a}_{t}^{b}$. 
(e) Solve for value of $M_{t+1}$ such that the free entry condition for fringe banks is satisfied with equality.

(f) Find $\zeta_{t+1}(a, \delta)$ using decision rules for fringe banks. That is.

$$
\begin{aligned}
\zeta_{t+1}\left(\tilde{a}, \delta^{\prime}\right)= & \sum_{i, j}\left(1-x^{f}\left(a_{i}, \delta_{j}, z_{t}, a_{t}^{b}, \bar{A}_{t}, M_{t}, z_{t+1}\right)\right) I_{\left\{\tilde{a}^{f}\left(a_{i}, \delta_{j}, z_{t}, a_{t}^{b}, \bar{A}_{t}, M_{t}, z_{t+1}\right)=\tilde{a}\right\}} G\left(\delta^{\prime}, \delta\right) \zeta\left(a_{i}, \delta_{j}\right) \\
& +G\left(\delta^{\prime}, \delta\right) E_{t} \sum_{\delta} I_{\left.\left\{a^{\prime}=a^{f, e}(\cdot)\right)\right\}} G^{f, e}(\delta)
\end{aligned}
$$

Compute $\bar{A}_{t+1}=\sum_{i, j} a_{i} \zeta_{t+1}\left(a_{i}, \delta_{j}\right)$.

(g) Continue for $T$ periods and collect $\left\{a_{t}^{b}, \bar{A}_{t}, M_{t}\right\}_{t=1}^{T}$.

(h) Estimate equations (54) and (55) to obtain new aggregate functions.

(i) If the new aggregate functions are close enough to those used to solve the bank problems and along the equilibrium path the distance between the solution to the auxiliary problem $\left(\ell^{f}\left(\bar{A}_{t}, z_{t}, a_{t}^{b}, M_{t}, \ell_{t}^{b} ; \bar{\delta}\right)\right)$ and the average loan of fringe banks $\left(\sum_{i, j} \ell_{t}^{f} \zeta_{t}\left(a_{i}, \delta_{j}\right) / M_{t}\right)$ are close enough you are done. If not, return to 2.

Table 15 presents the aggregate functions in the benchmark economy.

Table 15: Equilibrium Aggregate Functions

\begin{tabular}{l|c|c}
\hline \hline Function & $\log \left(\bar{A}^{\prime}\right)$ & $\log \left(M^{\prime}\right)$ \\
\hline $\operatorname{cons}$. & -0.753 & 0.012 \\
$\log (z)$ & -1.225 & -0.108 \\
$\log \left(a^{b}\right)$ & -0.040 & -0.002 \\
$\log (\bar{A})$ & -0.824 & 0.001 \\
$\log (M)$ & -0.202 & 0.580 \\
$\log \left(z^{\prime}\right)$ & 3.439 & 0.276 \\
\hline$R^{2}$ & 0.981 & 0.930 \\
\hline \hline
\end{tabular}

